Cochrane Database of Systematic Reviews

\title{
Mechanical bowel preparation for elective colorectal surgery
} (Review)

Güenaga KF, Matos D, Wille-Jørgensen P

Güenaga KF, Matos D, Wille-Jørgensen P.

Mechanical bowel preparation for elective colorectal surgery.

Cochrane Database of Systematic Reviews 2011, Issue 9. Art. No.: CD001544.

DOI: 10.1002/14651858.CD001544.pub4.

www.cochranelibrary.com 
TABLE OF CONTENTS

HEADER 1

ABSTRACT

PLAIN LANGUAGE SUMMARY

BACKGROUND

OBJECTIVES

METHODS

RESULTS

DISCUSSION

AUTHORS' CONCLUSIONS

ACKNOWLEDGEMENTS

REFERENCES

CHARACTERISTICS OF STUDIES

DATA AND ANALYSES

Analysis 1.1. Comparison 1 Mechanical bowel preparation versus no preparation, Outcome 1 Anastomosis leakage stratified for colonic or rectal surgery.

Analysis 1.2. Comparison 1 Mechanical bowel preparation versus no preparation, Outcome 2 Overall anastomotic leakage for colorectal surgery.

Analysis 1.3. Comparison 1 Mechanical bowel preparation versus no preparation, Outcome 3 Mortality.

Analysis 1.4. Comparison 1 Mechanical bowel preparation versus no preparation, Outcome 4 Peritonitis.

Analysis 1.5. Comparison 1 Mechanical bowel preparation versus no preparation, Outcome 5 Reoperation.

Analysis 1.6. Comparison 1 Mechanical bowel preparation versus no preparation, Outcome 6 Wound infection.

Analysis 1.7. Comparison 1 Mechanical bowel preparation versus no preparation, Outcome 7 Infectious extra-abdominal complications.

Analysis 1.8. Comparison 1 Mechanical bowel preparation versus no preparation, Outcome 8 Non-infectious extra-abdominal complications.

Analysis 1.9. Comparison 1 Mechanical bowel preparation versus no preparation, Outcome 9 Sensitivity analysis 1 - Including only studies with adequate randomisation.

Analysis 1.10. Comparison 1 Mechanical bowel preparation versus no preparation, Outcome 10 Sensitivity analysis 2 - Studies including only patients with anastomosis.

Analysis 2.1. Comparison 2 Mechanical bowel preparation versus rectal enema, Outcome 1 Anastomotic leakage for colorectal surgery.

Analysis 2.2. Comparison 2 Mechanical bowel preparation versus rectal enema, Outcome 2 Overall anastomotic leakage. .......

Analysis 2.3. Comparison 2 Mechanical bowel preparation versus rectal enema, Outcome 3 Mortality.

Analysis 2.4. Comparison 2 Mechanical bowel preparation versus rectal enema, Outcome 4 Peritonitis / Abscess. ...................

Analysis 2.5. Comparison 2 Mechanical bowel preparation versus rectal enema, Outcome 5 Reoperation. ................................

Analysis 2.6. Comparison 2 Mechanical bowel preparation versus rectal enema, Outcome 6 Wound infection. ......................... WHAT'S NEW

HISTORY

CONTRIBUTIONS OF AUTHORS

DECLARATIONS OF INTEREST

SOURCES OF SUPPORT

NOTES

INDEX TERMS

1

2

3

3

3

5

10

11

11

12

15

34

35

36

36

37

37

38

38

39

39

40

41

41

42

42

42

43

43

43

44

44

44

44

45

Mechanical bowel preparation for elective colorectal surgery (Review) 
[Intervention Review]

\section{Mechanical bowel preparation for elective colorectal surgery}

Katia F Güenaga1 ${ }^{1}$, Delcio Matos², Peer Wille-Jørgensen ${ }^{3}$

1Santos, Brazil. ${ }^{2}$ Gastroenterological Surgery, UNIFESP - Escola Paulista de Medicina, São Paulo, Brazil. ${ }^{3}$ Department of Surgical

Gastroenterology K, Bispebjerg Hospital, Copenhagen NV, Denmark

Contact address: Katia F Güenaga, Rua Ministro João Mendes, 60/31, Santos, São Paulo, 11040-260, Brazil. kfg012@terra.com.br.

Editorial group: Cochrane Colorectal Cancer Group

Publication status and date: New search for studies and content updated (no change to conclusions), published in Issue 9, 2011.

Citation: Güenaga KF, Matos D, Wille-Jørgensen P. Mechanical bowel preparation for elective colorectal surgery. Cochrane Database of Systematic Reviews 2011, Issue 9. Art. No.: CD001544. DOI: 10.1002/14651858.CD001544.pub4.

Copyright @ 2011 The Cochrane Collaboration. Published by John Wiley \& Sons, Ltd.

\section{A B S T R A C T}

\section{Background}

The presence of bowel contents during colorectal surgery has been related to anastomotic leakage, but the belief that mechanical bowel preparation (MBP) is an efficient agent against leakage and infectious complications is based on observational data and expert opinions only.

An enema before the rectal surgery to clean the rectum and facilitate the manipulation for the mechanical anastomosis is used for many surgeons. This is analysed separately

\section{Objectives}

To determine the security and effectiveness of MBP on morbidity and mortality in colorectal surgery.

\section{Search methods}

Publications describing trials of MBP before elective colorectal surgery were sought through searches of MEDLINE, EMBASE, LILACS, IBECS and The Cochrane Library; by handsearching relevant medical journals and conference proceedings, and through personal communication with colleagues.

Searches were performed December 1, 2010.

\section{Selection criteria}

Randomised controlled trials (RCTs) including participants submitted for elective colorectal surgery. Eligible interventions included any type of MBP compared with no MBP. Primary outcomes included anastomosis leakage - both rectal and colonic - and combined figures. Secondary outcomes included mortality, peritonitis, reoperation, wound infection, extra-abdominal complications, and overall surgical site infections.

\section{Data collection and analysis}

Data were independently extracted and checked. The methodological quality of each trial was assessed. Details of randomisation, blinding, type of analysis, and number lost to follow up were recorded. For analysis, the Peto-Odds Ratio (OR) was used as the default (no statistical heterogeneity was observed).

\section{Main results}

At this update six trials and a new comparison (Mechanical bowel preparation versus enema) were added. Altogether eighteen trials were analysed, with 5805 participants; 2906 allocated to MBP (Group A), and 2899 to no preparation (Group B), before elective colorectal surgery. 
For the comparison Mechanical Bowel Preparation Versus No Mechanical Bowel Preparation results were:

1. Anastomotic leakage for low anterior resection: 8.8\% (38/431) of Group A, compared with 10.3\% (43/415) of Group B; Peto OR 0.88 [0.55, 1.40].

2. Anastomotic leakage for colonic surgery: $3.0 \%$ (47/1559) of Group A, compared with 3.5\% (56/1588) of Group B; Peto OR 0.85 [0.58, 1.26 ].

3. Overall anastomotic leakage: 4.4\% (101/2275) of Group A, compared with 4.5\% (103/2258) of Group B; Peto OR 0.99 [0.74, 1.31].

4. Wound infection: $9.6 \%$ (223/2305) of Group A, compared with 8.5\% (196/2290) of Group B; Peto OR 1.16 [0.95, 1.42].

Sensitivity analyses did not produce any differences in overall results.

For the comparison Mechanical Bowel Preparation (A) Versus Rectal Enema (B) results were:

1. Anastomotic leakage after rectal surgery: 7.4\% (8/107) of Group A, compared with 7.9\% (7/88) of Group B; Peto OR 0.93 [0.34, 2.52 ].

2. Anastomotic leakage after colonic surgery: 4.0\% (11/269) of Group A, compared with 2.0\% (6/299) of Group B; Peto OR 2.15 [0.79, 5.84 ].

3. Overall anastomotic leakage: 4.4\% (27/601) of Group A, compared with 3.4\% (21/609) of Group B; Peto OR 1.32 [0.74, 2.36].

4. Wound infection: 9.9\% (60/601) of Group A, compared with 8.0\% (49/609) of Group B; Peto OR 1.26 [0.85, 1.88].

\section{Authors' conclusions}

Despite the inclusion of more studies with a total of 5805 participants, there is no statistically significant evidence that patients benefit from mechanical bowel preparation, nor the use of rectal enemas. In colonic surgery the bowel cleansing can be safely omitted and induces no lower complication rate. The few studies focused in rectal surgery suggested that mechanical bowel preparation could be used selectively, even though no significant effect was found. Further research on patients submitted for elective rectal surgery, below the peritoneal verge, in whom bowel continuity is restored, and studies with patients submitted to laparoscopic surgeries are still warranted.

\section{PLAIN LANGUAGE SUMMARY}

\section{Mechanical bowel preparation for elective colorectal surgery may not improve outcome for patients}

Until recently it was thought that vigorous preoperative mechanical cleansing of the bowel (mechanical bowel preparation), together with the use of oral antibiotics, reduced the risk of septic complications after non-emergency (elective) colorectal operations. Mechanical bowel preparation was performed routinely prior to colorectal surgery until 1972, when this procedure started to be questioned. Well designed clinical trials were published, and their results caused some colorectal surgeons to doubt this traditional belief.

This review has identified all known trials that compared any kind of mechanical bowel preparation with no preparation (Comparison 1) and mechanical bowel preparation with rectal enema (Comparison 2) in patients submitted to elective colorectal surgery. Five new trials have been included in this third update of the review, bringing the total number of included trials to 18 (5805 participants). Analysis of these 18 trials showed no statistically significant differences in how well the three groups of patients (mechanical bowel preparation group, no preparation group and rectal enemas) did after surgery in terms of leakage at the surgical seam of the bowel ends, mortality rates, peritonitis, need for reoperation, wound infection, and other non-abdominal complications. Consequently, there is no evidence that mechanical bowel preparation improves the outcome for patients. Further research on mechanical bowel preparation or enemas versus no preparation in patients submitted for elective rectal surgery and laparoscopic colorectal surgery is warranted. 


\section{B A C K G R O U N D}

For more than a century surgeons have believed, dogmatically, that efficient mechanical bowel preparation is an important factor in preventing infectious complications and anastomotic dehiscence (splitting open of a surgical join) after colorectal surgery (Halsted 1887; Thornton 1997). Clinical experiences and observational studies have shown that mechanical removal of gross faeces from the colon has been associated with decreased morbidity and mortality in patients undergoing operations of the colon (Nichols 1971). Authors were categorical that the most important factor to affect the outcome of a colonic operation that is within the control of a surgeon, is the degree of emptiness of the bowels (Chung 1979; Clarke 1977).

An early randomised clinical trial questioned this dogma, and concluded that vigorous mechanical bowel preparation was not necessary (Hughes 1972), stating: "omission of enemas and bowel washes from the preoperative procedures will be welcomed by both patients and nursing staff". The authors of another metaanalysis concurred with this point of view (Slim 2004), while in another trial (Irving 1987), the authors argued that preoperative bowel preparation is time-consuming and expensive, unpleasant to the patients - even dangerous on occasion (increased risk for inflammatory processes (Bucher 2005)) - and completely unnecessary.

Different methods of mechanical bowel preparation have been tested and approved. The potential danger of having faeces in contact with a newly performed anastomosis has led to the construction of a defunctioning stoma when colon was not prepared (Grabham 1995; Mealy 1992). Both experimental studies (O' Dwyer 1989; Schein 1995; Smith 1983), and clinical trials in emergency surgery (Dorudi 1990; Duthie 1990), have been published in order to support this theory.

In a review of literature in 1998 (Platell 1998), Platell and colleagues concluded that there was limited evidence in the literature to support the use of mechanical bowel preparation in patients undergoing colorectal surgery. The same principal author conducted a randomised trial comparing single phosphate enema with polyethylene glycol (PEG) before colorectal surgery, and found the results favoured the group that received PEG for bowel preparation (Platell 2006).

In 2002, Fa-Si-Oen was co-author in a study that prospectively evaluated a consecutive series of patients who underwent resection and primary anastomosis, and he concluded that: "mechanical bowel preparation is not a sine qua non for safe colorectal surgery" (van Geldere 2002).

The authors of a trial that analysed the bowel contents suggested that participants receiving mechanical bowel preparation had a tendency toward a higher incidence of bowel contents spillage compared with participants who did not receive it, but without statistical significance. Spillage of bowel contents into the peritoneal cavity may increase the rate of postoperative complications (Mahajna 2005).

A recent case-control study that analysed patients with rectal cancer who submitted to elective resection with mesorectal excision (the mesorectum is a fatty tissue directly adjacent to the rectum that contains blood vessels and lymph nodes) concluded that, "elective rectal surgery for cancer without mechanical bowel preparation may be associated with reduced postoperative morbidity" (Bretagnol 2007).

In the first version of this review there were only five included trials (Brownson 1992; Burke 1994; Fillmann 1995; Miettinen 2000; Santos 1994). The first update included four more studies (Bucher 2005; Fa-Si-Oen 2005; Tabusso 2002; Zmora 2003). The second update included five trials (Contant 2007; Jung 2006; Jung 2007; PenaSoria 2007; Ram 2005).

At this update six more trials are included (Bretagnol 2010; Leiro 2008; Moral 2009; Platell 2006; Scabini 2010; Van't Sant 2010).

At the first publication of this review we suggested that any cleaning of the rectum could facilitate manipulation at the time of the mechanical anastomosis. Some authors (Bucher 2005; Moral 2009; Platell 2006; Scabini 2010; Zmora 2003) had such conduct. The authors of this review have decided to separate these trials into a new comparison: Mechanical bowel preparation versus rectal enema: one group of patients submitted to a mechanical bowel preparation and other without mechanical bowel preparation and just a cleaning of the rectum with enemas.

\section{OB JECTIVES}

To determine the effectiveness and risk of prophylactic mechanical bowel preparation for morbidity and mortality rates in colorectal surgery, with anastomotic leakage as the primary outcome.

As the incidence of anastomotic dehiscence is increasing the closer to anus the anastomosis is applied (Goligher 1970), bowel preparation might have different effect in colon and rectum, therefore the analyses were stratified for colonic and rectal surgery, as well as for colorectal surgery as a whole.

Some trials involving participants of rectal surgeries were conducted comparing groups of patients submitted to a rectal enema (in order to clean the rectum at the moment of anastomosis) with groups of patients submitted a mechanical bowel preparation. The reviewers decided to analyse these trials separately.

The aim of the update is to determine whether mechanical bowel preparation before elective colorectal surgery is really essential for patients.

\section{METHODS}

\section{Criteria for considering studies for this review}

\section{Types of studies}

\section{Inclusion criteria}

(i) Randomised clinical trials comparing preoperative mechanical bowel preparation versus no preparation and/or rectal enema (or placebo) in

(ii) participants undergoing elective colorectal surgery and in which (iii) the primary outcome (anastomotic leakage) is clearly stated in both treatment arms.

All three criteria must be met for inclusion of a trial.

Exclusion criteria

(i) Studies evaluating two or more different cleansing methods. 
(ii) Studies including participants undergoing emergency surgery.

\section{Types of participants}

Patients undergoing elective colorectal surgery. Both adults and children are eligible for inclusion.

\section{Types of interventions}

Comparasion 1: Any strategy in mechanical bowel preparation compared with no mechanical bowel preparation.

Comparasion 2: Any strategy in mechanical bowel preparation compared with rectal enema.

\section{Types of outcome measures}

\section{Primary outcome measures}

(i) Anastomotic leakage (defined as a discharge of faeces from the anastomosis site, that externalises through the drainage opening or the wound incision; or can be characterised on the basis of an abscess adjacent to the site) confirmed by clinical or radiological investigation.

The types of surgery and sites of anastomosis were stratified into:

(a) low anterior resection with extra-peritoneal anastomosis (rectum considered to be extra-peritoneal); and

(b) colonic surgery with intra-peritoneal anastomosis.

(ii) Overall anastomotic leakage: total number of anastomotic dehiscences in trials (in all of colon and rectum).

\section{Secondary outcome measures}

(iii) Mortality: number of postoperative deaths related to the surgery.

(iv) Peritonitis: presence of postoperative infections in the abdominal cavity, localised (abscess) or not.

(v) Reoperation: surgical re-intervention for anastomotic complication or peritonitis.

(vi) Wound infection: defined as a discharge of pus from the abdominal wound.

(vii) Infectious extra-abdominal complication: postoperative infectious complication at extra-abdominal site.

(viii) Non-infectious extra-abdominal complication (e.g. deep venous thrombosis, cardiac complications, wound rupture).

\section{Sensitivity and subgroup analyses}

(ix) Anastomotic leakage and wound infection in studies with adequate randomisation.

(x) Anastomotic leakage and wound infection in studies in which bowel continuity was restored.

\section{Search methods for identification of studies}

See: Collaborative Colorectal Cancer Review Group search strategy (Wille-Jørgensen 1999).

The studies were identified from the following sources: Cochrane Colorectal Cancer Group Specialised Register, Cochrane Central Register of Controlled Trials, MEDLINE, EMBASE, CINAHL, LILACS, IBECS, SCISEARCH, and the Controlled Clinical Trials Database.

We searched for additional trials by checking the reference lists of relevant papers, writing to experts in the field, handsearching journals, and by contacting the authors of relevant trial papers. Conference proceedings from major gastrointestinal conferences (World Congress of Gastroenterology, annual meetings of the American Society of Colon and Rectal Surgery, annual meetings of the Association of Coloproctology of Great Britain and Ireland, annual meetings of the European Association of Coloproctology, and the Tripartites meetings) were scrutinised back to 1994 (last possible retrieval of abstract material). No language restrictions, nor date restrictions were applied in the searches. Searches were performed December 12010.

Some data were completed in a personal communication with authors, which made possible the stratification, of the surgery (rectal or colonic), in some studies.

\section{Search strategy}

\#1 Cochrane Collaboration search strategy for RCTs (Higgins 2008) \#2 tw INTESTIN* or tw BOWEL

\#3 tw LARGE or tw GROSSO or tw GRUESO

\#4 \#2 and \#3

\#5 tw COLO* or tw CECO

\#6 tw RECT* or tw $\mathrm{RET}^{\star}$

\#7 \#4 or \#5 or \#6

\#8 \#3 and \#7

\#9 tw PREPARA

\#10 tw SURGERY or SURGICAL

$\# 11$ \#8 and \#9 and \#10

\#12 \#1 and \#11

\section{Data collection and analysis}

\section{Locating and selecting studies}

The reviewers selected the trials to be included in this review independently. Disagreements about selection were resolved by consensus (via e-mail correspondence). Sometimes unpublished studies were identified through personal contact with the authors and thus were included.

\section{Critical appraisal of studies}

The methodological quality of each trial was assessed by at least two of the authors. Details of the randomisation method, blinding, and whether an intention-to-treat analysis was done, and the number of participants lost to follow up was recorded, thus enabling the risk of bias in individual studies to be evaluated (Higgins 2008). The external validity of the studies was assessed by analysis of the characteristics of participants and the interventions as listed below. Disagreements were solved by consensus.

\section{Participants}

Category of disease (colorectal cancer, inflammatory disease, megacolon, polyposis, diverticular disease), sex of participants, age, topography of the affected area, operative procedure, antibiotic therapy, and surgeon experience were evaluated for each study. Pre-study calculation of the sample size and whether the sample was representative were registered. Duplicate publications of the same set of data were identified, and each sample of participants was only included once.

\section{Collecting data}

Studies where the allocation concealment was deemed to be adequate were included. Where the allocation procedure was unclear, studies were included if the primary authors stated that it was a randomised study, but these studies were excluded from a sensitivity analysis. Data were independently extracted by at least two of the reviewers, and cross-checked. The results of each trial 
were summarised in $2 \times 2$ tables for each outcome. Disagreements were solved by consensus.

\section{Interventions}

Comparasion 1: types of mechanical bowel preparation: anterograde (oral) or retrograde (enemas) versus no mechanical bowel preparation.

Comparasion 2: types of mechanical bowel preparation: anterograde (oral) versus rectal enema.

Data were entered into Review Manager 5 (version 5.0.25) by single data-entry (KFG), with the consent of an author (DM); all dataentries were controlled by a second author (PWJ).

\section{Analysing and presenting results}

Where appropriate, the studies were stratified for different metaanalyses according to the analysis of the defined outcomes. The meta-analyses were performed using various techniques (Review Manager 5): for dichotomous outcome measures, the combined logarithm of the Peto Odds Ratio (fixed-effect model) was used as the default. A test for statistical heterogeneity was performed in each case. Where heterogeneity was encountered, results were reported as Odds Ratio (OR) using random-effects modelling. For the analysis, only participants submitted for elective colorectal surgery were reviewed; according to type of intervention and type of participant, to assess whether there were important differences between them. All inclusion criteria had to be met.

The included studies were assessed to determine whether clinical and statistical heterogeneity were present.

Potential publication bias in the results of the meta-analysis was assessed both by inspection of graphical presentations (by means of a funnel plot: plotting the study weight or sample size [on the $Y$ axis] against the $O R$ [on the $x$ axis]), and by calculating a test of heterogeneity (standard chi-squared test on $\mathrm{N}$ degrees of freedom where $\mathrm{N}$ equals the number of trials contributing data minus one). The funnel plot was possible only for an outcome described in more than five trials. Three possible reasons for heterogeneity were pre-specified: (i) that responses differ according to difference in the quality of the trial; (ii) that responses differ according to sample size; (iii) that responses differ according to clinical heterogeneity. When heterogeneity was discovered, sensitivityanalyses were performed in subgroups.

\section{Sensitivity analysis}

Was performed for anastomotic leakage and wound infection in studies with adequate randomisation and studies in which bowel continuity was restored. Since the random-effects model provides a more conservative estimate of an overall effect, it was used as the default in these sensitivity analyses.

\section{Improving and updating this review}

Updates are considered on an biannual basis. The first update was performed in 2005, two years after first publication in The Cochrane Library. The second update was postponed until four years after the first update. This third update was realized two years after the second update, including one new comparison.

\section{RES U L T S}

\section{Description of studies}

At the initial publication five studies (Brownson 1992; Burke 1994; Fillmann 1995; Miettinen 2000; Santos 1994) were included. A total of 824 patients were allocated to mechanical bowel preparation (Group $A=408$ ) and no preparation (Group B = 416). The authors concluded that the evidence found were insufficient to demonstrate significant differences between the use or absence of preoperative mechanical preparation of the colon in elective colorectal surgery. The expectation was that the results were favourable to the mechanical bowel preparation, but it did not happen. The doubt for rectal resection was raised and the authors suggested a single enema before surgery and highlighted to the necessity of the new trials answering this question.

The first update included four new trials (Bucher 2005; Fa-SiOen 2005; Tabusso 2002; Zmora 2003). Eight hundred and thirty extra patients were allocated: 414 in Group A and 416 in Group B. Although some clinical and methodological heterogeneity exists between the outcomes of the individual studies, the authors suggested that mechanical bowel preparation before colorectal surgery has not been proven beneficial. It seems that preparation is associated with a higher frequency of anastomotic leakage - and thus should be omitted.

Five new trials were added in the second update (Contant 2007; Jung 2006; Jung 2007; Pena-Soria 2007; Ram 2005), with 3167 extra patiens (Group A $=1595$; Group $B=1572$ ). The conclusion did not change: there is no statistically evidence that surgeons must clean the bowel before every elective colorectal surgery. The belief that mechanical bowel preparation is necessary before elective colorectal surgery should be reconsidered.

At this third update with six new trials (Bretagnol 2010; Leiro 2008; Moral 2009; Platell 2006; Scabini 2010; Van't Sant 2010) and the authors included a new comparison, distributing the studies according to the control group: without mechanical bowel preparation (Comparasion 1) and rectal enema cleaning (Comparasion 2). Nine hundred eighty extra patients were included (Group A = 493; Group B = 495).

Data from two studies included in this review (Jung 2006; Van't Sant 2010) will be addressed to only for a few outcomes because they are a subgroup analysis of others (Jung 2007; Contant 2007).

Altogether this review included nineteen published studies and one unpublished (Jung 2006), analysing a total of 5805 patients allocated in:

Comparision 1: Mechanical bowel preparation versus no preparation (Bretagnol 2010; Brownson 1992; Burke 1994; Contant 2007; Fa-Si-Oen 2005; Fillmann 1995; Jung 2006; Jung 2007; Leiro 2008; Miettinen 2000; Pena-Soria 2007; Ram 2005; Santos 1994; Tabusso 2002; Van't Sant 2010): Group A $=2305$ and Group B = 2290.

Comparision 2: Mechanical bowel preparation versus rectal enema (Bucher 2005; Moral 2009; Platell 2006; Scabini 2010; Zmora 2003): Group A = 601 and Group B = 609 .

Including publication and updates seven trials were excluded because numerous reasons: analysed a series of participants (Dorudi 1990); without control group (Duthie 1990; Irving 1987); 
data from conference proceeding without more details (Hughes 1972); because it was a retrospective study (Memon 1997); a casecontrol study (Bretagnol 2007); testing antimicrobials (Matheson 1978).

Most of the studies were published in English, and found on MEDLINE; though one was published in Portuguese (Fillmann 1995), and three in Spanish (Leiro 2008; Moral 2009; Tabusso 2002); three were found on the LILACS database and one on the IBECS (Moral 2009).

Eight of the included trials were multicenter (Bretagnol 2010; Bucher 2005; Contant 2007; Fa-Si-Oen 2005; Jung 2006; Jung 2007; Miettinen 2000; Zmora 2003).

As previously mentioned, two studies were a subgroup analysis of multicenter trials and analysed only the participants of rectal surgery. One, unpublished study (Jung 2006), from the large Swedish study (Jung 2007); the other one, published (Van't Sant 2010), from the Netherlands trial (Contant 2007). The data were used separately in the stratified analyses only. In all other outcomes the data were compiled with those, in which these participants originally had been included.

The educational status of the surgeon were described as follows: three studies described the operations performed by a consultant surgeon or under supervision by a consultant (Burke 1994; FaSi-Oen 2005; Miettinen 2000); two studies described operations as having been performed by a colorectal surgeon or under supervision of a colorectal surgeon (Ram 2005; Santos 1994); in one study the procedures were performed by one of three attending surgeons (Platell 2006); In one study (Pena-Soria 2007), all surgery was performed by one surgeon only; Jung 2007 mentioned that the surgeons involved in the trial specialised in colorectal surgery; Scabini 2010 described that 5 surgeons with high specialisation in colorectal resection were enrolled in the study. The other trials did not describe the experience of the surgeons.

The Zmora study was published three times: first as an abstract (Zmora 2002), then as a full article (Zmora 2003), and finally as an article analysing only those participants who underwent left-sided colonic anastomosis (Zmora 2006).

Four authors of included studies (Fillmann 1995; Jung 2007; Santos 1994; Zmora 2003) provided supplementary data directly to the reviewers (PWJ or KFG).

\section{Types of participants}

The inclusion criteria were the same for all studies, i.e. participants admitted for elective colorectal surgery.

One trial included children (Santos 1994); other patients above 16 years of age (Miettinen 2000). Some studies included patients aged 18 years or older (Bretagnol 2010; Jung 2007; Pena-Soria 2007; Platell 2006, Contant 2007) or only adults (Ram 2005).

Some trials included all colorectal procedures as well as abdominoperineal excision of the rectum, Hartman's procedure, defunctioning colostomy (Fillmann 1995; Leiro 2008; Ram 2005; Santos 1994). Some of them included participants without anastomosis (Brownson 1992; Fillmann 1995; Leiro 2008; Santos 1994; Tabusso 2002); two studies excluded these participants in the outcome - anastomosis leakage - (Brownson 1992; Leiro 2008); four studies excluded participants in whom bowel continuity was not restored (Burke 1994; Miettinen 2000; Platell 2006; Scabini 2010). Two of the trials included participants who were submitted only for elective "left-sided" colorectal surgery with an anastomosis (Bucher 2005; Fa-Si-Oen 2005). Three studies included only participants with colorectal cancer (Bretagnol 2010; Scabini 2010; Tabusso 2002). Three of the trials included laparoscopic procedures (Bretagnol 2010; Bucher 2005; Moral 2009), while laparoscopic surgery was an exclusion criterion in other studies (Jung 2007; Platell 2006). Some trials set the limits of the inclusion criteria the realisation of primary anastomosis (Contant 2007; Leiro 2008; Jung 2007; Moral 2009; Pena-Soria 2007; Platell 2006). In two of the trials anastomosis below the peritoneal line was not included ( $\mathrm{Fa}$ Si-Oen 2005; Pena-Soria 2007). In one trial high colorectal surgery was included, but not low rectal surgery (Jung 2007). Some studies performed a temporary decompression: ileostomy or colostomy (Bretagnol 2010; Moral 2009; Platell 2006).

Most trials specified exclusion criteria, but these varied tremendously between trials (see 'Characteristics of included studies' table for details). Three trials did not provide details of any exclusion criteria (Brownson 1992; Moral 2009; Tabusso 2002), while others no participants were excluded (Bucher 2005; Fa-Si-Oen 2005; Fillmann 1995; Miettinen 2000; Ram 2005).

\section{Types of interventions}

Some studies compared no mechanical bowel preparation with a method of mechanical preparation: polyethylene glycol electrolyte (PEG) solution; laxatives (mineral oil, agar and phenolphthalein); mannitol; enemas (900 ml water containing $100 \mathrm{ml}$ glycerin); sodium picosulphate $10 \mathrm{mg}$; Bisacodyl $(10 \mathrm{mg})$ and enemas; and diets: low residue, non-residue and only with clear liquids.

In this new comparison the authors divided the participants in two groups: one of them had the bowel cleaned with any kind of preparation and a second one group had only a rectal enema.

The duration of follow up varied between trials, and ranged from seven days after surgery (Burke 1994) to three months (Fa-SiOen 2005); four of them did not describe the time (Brownson 1992; Leiro 2008; Ram 2005; Tabusso 2002). For full details see the 'Characteristics of included studies' table.

The methods used to cleanse the bowel were mannitol (Fillmann 1995); polyethylene glycol (Brownson 1992; Fa-Si-Oen 2005; Miettinen 2000); sodium phosphate solution (Burke 1994; Ram 2005) and some trials participants were submitted more than one method (Bretagnol 2010; Contant 2007; Jung 2007; Leiro 2008; Pena-Soria 2007; Santos 1994; Tabusso 2002).

Five trials (Bucher 2005; Moral 2009; Platell 2006; Scabini 2010; Zmora 2003) were analysed separately in this update. The authors reported an enema of saline solution before surgery for participants scheduled for rectal surgery compared with a group submitted to mechanical bowel preparation (polyethylene glycol or sodium phosphate solution). 


\section{Types of outcome measurements}

\section{Primary outcomes}

\section{Anastomotic leakage}

Three studies stratified the anastomosis between rectal and colon (Burke 1994; Leiro 2008; Miettinen 2000). Stratification data were obtained through personal contact with three trial authors (Jung 2006; Santos 1994; Zmora 2003). (Van't Sant 2010) analysed separately the rectal surgery of the trial performed by (Contant 2007).

\section{Overall anastomotic leakage}

All the included trials described this outcome.

\section{Secondary outcomes}

\section{Mortality}

Thirteen trials reported mortality (Bretagnol 2010; Burke 1994; Contant 2007; Jung 2007; Leiro 2008; Miettinen 2000; Moral 2009; Pena-Soria 2007; Platell 2006; Ram 2005; Scabini 2010; Van't Sant 2010; Zmora 2003). Some of them, this outcome was implicit in the text (Bucher 2005; Fillmann 1995; Jung 2007; Santos 1994; Tabusso 2002).

\section{Peritonitis}

Fifteen trials reported this outcome (Bretagnol 2010; Bucher 2005; Brownson 1992; Contant 2007; Fillmann 1995; Jung 2007; Leiro 2008; Miettinen 2000; Moral 2009; Pena-Soria 2007; Platell 2006; Ram 2005; Scabini 2010; Tabusso 2002; Zmora 2003).

\section{Reoperation}

Twelve trials reported reoperation as an outcome (Bretagnol 2010; Bucher 2005; Burke 1994; Contant 2007; Fa-Si-Oen 2005; Fillmann 1995; Jung 2007; Leiro 2008; Miettinen 2000; Platell 2006; Ram 2005; Santos 1994).

\section{Wound infection}

Wound infection was reported in all trials.

\section{Infectious extra-abdominal complication}

Eight trials reported infectious extra-abdominal complications (Bretagnol 2010; Bucher 2005; Contant 2007; Fillmann 1995; Jung 2007; Miettinen 2000; Moral 2009; Platell 2006; Ram 2005).

\section{Non-infectious extra-abdominal complications}

Seven trials reported non-infectious extra-abdominal complications (Bretagnol 2010; Bucher 2005; Burke 1994; Fillmann 1995; Jung 2007; Miettinen 2000; Platell 2006; Ram 2005; Zmora 2003).

\section{Other characteristics}

Sample size was calculated in eight studies (Bretagnol 2010; Bucher 2005; Contant 2007; Fa-Si-Oen 2005; Fillmann 1995; Jung 2007; Moral 2009; Pena-Soria 2007); the author of one of these trials answered our correspondence (Fillmann 1995). Three of the trials described the sample as consecutive (Burke 1994; Miettinen 2000; Ram 2005). Intention-to-treat analysis was applied in four trials (Bretagnol 2010; Fa-Si-Oen 2005; Jung 2007; Platell 2006). Two trials assessed external validity (Contant 2007; Jung 2007).
Sensitivity analysis and subgroup analyses on anastomotic leakage and wound infection

The allocation method was not well-described In three of the studies (Brownson 1992; Burke 1994; Tabusso 2002), and was inadequate in one study (Ram 2005). A sensitivity analysis was performed leaving out these studies (outcome 9). Five of the trials included participants without anastomosis and an analysis was carried out without these studies (outcome 10) (Fillmann 1995; Leiro 2008; Ram 2005; Santos 1994; Tabusso 2002).

\section{Risk of bias in included studies}

\section{Selection bias}

Selection bias consists of systematic differences in the comparison groups.

The allocation procedures used were:

- An interactive voice randomisation system (Bretagnol 2010);

- Computer generated randomisation (Bucher 2005; Pena-Soria 2007; Scabini 2010; Zmora 2003);

- Sealed envelops (Contant 2007; Leiro 2008; Miettinen 2000; Moral 2009);

- Central trial office (Fa-Si-Oen 2005; Jung 2007);

- Random number table (Fillmann 1995; Platell 2006);

- Randomised cards (Santos 1994);

- According to identification numbers at the hospital (Ram 2005).

In the other trials the allocation process was not clearly specified (Brownson 1992; Burke 1994; Tabusso 2002), and thus considered unclear, which lead to the planned sensitivity analysis.

In general, allocation concealment was not sufficiently described in the earlier trials, but in this update, the authors' concern with the quality of this characteristic is evident:

- (Bretagnol 2010; Bucher 2005; Contant 2007; Fa-Si-Oen 2005; Fillmann 1995; Jung 2007; Leiro 2008; Miettinen 2000; Moral 2009; Pena-Soria 2007; Platell 2006; Santos 1994; Scabini 2010; Zmora 2003) had adequate allocation concealment (graded A), and the process of randomisation was well defined;

- (Brownson 1992; Burke 1994; Tabusso 2002) had the allocation concealment unclear (Grade B);

- In (Ram 2005), the allocation concealment was considered inadequate (grade $\mathrm{C}$ ) because the authors utilised the identification number of the participants (even or odd) to determine randomisation.

\section{Performance bias}

Performance bias consists of systematic differences in care provided, apart from the intervention being evaluated.

Some trials described the two allocation groups as being equal according to gender, age, types of operation, and diagnosis (Bucher 2005; Burke 1994; Fa-Si-Oen 2005; Fillmann 1995; Miettinen 2000; Moral 2009; Santos 1994; Scabini 2010; Zmora 2003). One trial 
did not give details (Brownson 1992). One called attention to the statistical difference between the two groups with regard to age, haemoglobin level and serum albumin (Tabusso 2002). One of them reported the homogeneity of the groups but did not give details of the exact number of male and female participants (Platell 2006).

All trials used prophylactic antibiotics according to the guideline of each hospital, administered to all patients with or without mechanical bowel preparation, intravenously at anaesthetic induction and were continued 24 hours after surgery.

\section{Blinding}

Double-blind study (orange juice as a placebo): (Fillmann 1995).

Single-blind studies (the operating surgeon was blinded to the randomisation process and preparation status of all patients; surgeons were aware whether bowel preparation had taken place or not; investigators assessing the endpoints were blinded to the use of mechanical bowel preparation; the participating surgeons did not know the size of the blocks of permutations, and the hospital charts of participants were reviewed by a statistician and a surgeon who were not involved in conducting the study; participants were followed by an independent observer: (Bretagnol 2010; Bucher 2005; Burke 1994; Jung 2007; Pena-Soria 2007; Platell 2006).

Not blinded: (Contant 2007; Tabusso 2002).

Information about blinding was not provided in the other trials: (Brownson 1992; Fa-Si-Oen 2005; Leiro 2008; Miettinen 2000; Moral 2009; Ram 2005; Santos 1994; Scabini 2010; Zmora 2003).

\section{Attrition bias}

Attrition bias occurs when there are systematic differences in withdrawals from a trial.

Some trials did not describe withdrawals or dropouts: (Brownson 1992; Leiro 2008; Moral 2009; Ram 2005; Scabini 2010; Tabusso 2002).

Some of them had withdrawals and no dropouts: (Burke 1994; Contant 2007; Pena-Soria 2007; Platell 2006; Santos 1994; Zmora 2003).

Withdrawals and dropouts occurred in: (Bretagnol 2010; Jung 2007).

In four of the trials all participants completed the study: (Bucher 2005; Fa-Si-Oen 2005; Fillmann 1995) (personal correspondence); (Miettinen 2000).

\section{Detection bias}

Detection bias occurs when there are systematic differences in assessment of outcomes.

(Bretagnol 2010) used routine contrast enema before ileostomy closure (anastomotic leakage asymptomatic) and if symptoms related to leakage were noted (clinical anastomotic leakage).

In the first half of the Burke study (Burke 1994), the incidence of anastomotic leaks was established by means of water-soluble contrast enemas in all participants, but in the second half of the study enemas were used only on clinical suspicion of leakage. This was because two of the six leaks identified on the seventh day after surgery occurred immediately after administration of the routine water-soluble contrast enema.

In (Platell 2006), all patients who underwent low or ultra low anterior resection (most of whom also had a defunctioning ileostomy) had a routine enema within 4 weeks of surgery. This was not done in patients with intra-abdominal anastomosis.

With regard to the diagnostics of the various outcomes, the following trials:

a) did not describe the methodology (Brownson 1992; Jung 2007; Tabusso 2002);

b) used clinical symptoms or/and laboratory results (Bucher 2005; Burke 1994; Contant 2007; Fa-Si-Oen 2005; Leiro 2008; Moral 2009; Pena-Soria 2007; Ram 2005; Santos 1994; Scabini 2010);

c) used laboratory results in participants in whom the clinical diagnostic was unclear (Fillmann 1995);

d) described all of the methods used for diagnosing the complications (Bucher 2005; Contant 2007; Fa-Si-Oen 2005; Miettinen 2000; Pena-Soria 2007; Ram 2005; Zmora 2003).

For additional information about the included studies, see the 'Characteristics of included studies' table.

\section{Effects of interventions}

\section{Preparation versus non-preparation (comparison 01.00.00)}

Of the 4595 participants in the 15 included randomised controlled trials 2305 were allocated for mechanical bowel preparation (Group A), and 2290 for no preparation (Group B), before elective colorectal surgery.

\section{Primary outcomes}

(i) Anastomotic leakage (stratified)

\section{(a) Low anterior resection}

Eight-point-eight percent of participants in Group A (38 out of 431) who were submitted to low anterior resections had anastomotic leakage, compared with $10.3 \%$ in Group B (43 out of 415 ); the Peto OR was 0.88 (95\% confidence interval $(\mathrm{Cl})$ : 0.55, 1.40 (nonsignificant)), and there was no statistical heterogeneity (Bretagnol 2010; Burke 1994; Jung 2006; Leiro 2008; Miettinen 2000; Santos 1994; Van't Sant 2010);

\section{(b) Colonic surgery}

Three-point-zero percent of participants in Group A (47 out of 1559) who were submitted to colonic surgery had the diagnosis of anastomotic leakage, compared with 3.5\% (56 out of 1588) in Group $\mathrm{B}$; the Peto OR was 0.85 (95\% Cl: 0.58, 1.26 (non-significant)), and there was no statistical heterogeneity (Burke 1994; Contant 2007; Fa-Si-Oen 2005; Jung 2007; Leiro 2008; Miettinen 2000; Pena-Soria 2007; Santos 1994);

\section{(ii) Overall anastomotic leakage}

Overall anastomotic leakage was $4.4 \%$ in Group A (101 out of 2275 participants), compared with $4.5 \%$ (103 of 2258 participants) in Group B; the Peto OR was 0.99 ( $95 \% \mathrm{Cl}$ : 0.74, 1.31 (non-significant)). The chi-squared test for heterogeneity gave: $\mathrm{Chi}^{2}=20.93, \mathrm{df}=12$ $(P=0.05) ; I^{2}=43 \%$ (Bretagnol 2010; Brownson 1992; Burke 1994; Contant 2007; Fa-Si-Oen 2005; Fillmann 1995; Jung 2007; Leiro 
2008; Miettinen 2000; Pena-Soria 2007; Ram 2005; Santos 1994; Tabusso 2002).

\section{Secondary outcomes}

\section{(iii) Mortality}

One-point-six percent of participants in Group A (35 out of 2094) died, compared with $1.8 \%$ (38 out of 2072) in Group B; the Peto OR was 0.93 (95\% Cl: 0.58 to 1.47 (non-significant)); there was no statistical heterogeneity (Bretagnol 2010; Burke 1994; Contant 2007; Fillmann 1995; Jung 2007; Leiro 2008; Miettinen 2000; PenaSoria 2007; Ram 2005; Santos 1994).

\section{(iv) Peritonitis}

Two-point-two percent of participants in Group A (45 out of 1999) suffered peritonitis compared with $3.0 \%$ (61 of 1984) in Group B; the Peto OR was 0.74 (95\% Cl: 0.50 to 1.08 (non-significant)). The chisquared test for heterogeneity gave: $\mathrm{Chi}^{2}=19.38, \mathrm{df}=9(\mathrm{P}=0.02)$; $I^{2}=54 \%$ (Bretagnol 2010; Brownson 1992; Contant 2007; Fillmann 1995; Jung 2007; Leiro 2008; Miettinen 2000; Pena-Soria 2007; Ram 2005; Tabusso 2002).

\section{(v) Reoperation}

Six-point-one percent of participants in Group A (133 out of 2171 ) required reoperation compared with $5.8 \%$ (125 out of 2148) participants in Group B; the Peto OR was 1.06 (95\% Cl: 0.83 to 1.37 (non-significant)), and with no statistical heterogeneity (Bretagnol 2010; Burke 1994; Contant 2007; Fa-Si-Oen 2005; Fillmann 1995; Jung 2007; Leiro 2008; Miettinen 2000; Ram 2005; Santos 1994; Tabusso 2002).

\section{(vi) Wound infection}

Nine-point-six percent of participants in Group A (223 out of 2305) suffered from wound infection compared with 8.5\% (196 of 2290 participants) in Group B; the Peto OR was 1.16 (95\% Cl: 0.95 to 1.42 (non-significant)), and with no statistical heterogeneity (Bretagnol 2010; Brownson 1992; Burke 1994; Contant 2007; Fa-Si-Oen 2005; Fillmann 1995; Jung 2007; Leiro 2008; Miettinen 2000; Pena-Soria 2007; Ram 2005; Santos 1994; Tabusso 2002).

\section{(vii) Infectious extra-abdominal complications}

Eleven-point-four percent of participants in Group A ( 207 out of 1804) acquired infectious extra-abdominal complications compared with $11.1 \%$ (197 of 1771) in Group B; the Peto OR was 1.05 (95\% Cl: 0.85 to 1.30 (non-significant)), and with no statistical heterogeneity (Bretagnol 2010; Contant 2007; Fillmann 1995; Jung 2007; Miettinen 2000; Ram 2005).

\section{(viii) Non-infectious extra-abdominal complications}

Six-point-four percent of participants in Group A (77 out of 1189) acquired non-infectious extra-abdominal complications compared with $6.6 \%$ of participants (77 out of 1157 ) in Group B); the Peto OR was 0.98 (95\% Cl: 0.71 to 1.36 (non-significant)), with no statistical heterogeneity (Bretagnol 2010; Burke 1994; Fillmann 1995; Jung 2007; Miettinen 2000; Ram 2005).

\section{Analyses}

Random-effects model was applied in the outcomes analysed for all the studies, i.e. anastomotic leakage and wound infection:

\section{(ix) Trials with adequate randomisation}

Analysing only trials with adequate randomisation with the outcome overall anastomotic leakage and wound infection, showed no significant differences as well ( $p$ values: Group $A=0.46$ and Group B = 0.27) (Bretagnol 2010; Contant 2007; Fa-Si-Oen 2005; Fillmann 1995; Jung 2007; Leiro 2008; Miettinen 2000; Pena-Soria 2007; Santos 1994).

\section{(x) Studies in which bowel continuity was restored}

Analysing only trials with bowel continuity restored with the outcome overall anastomotic leakage, showed no difference either ( $p$ values for Group A $=0.71$ and Group B $=0.53$ ) (Bretagnol 2010; Brownson 1992; Burke 1994; Contant 2007; Fa-Si-Oen 2005; Jung 2007; Miettinen 2000; Pena-Soria 2007).

Funnel-plots performed on overall leakage and wound infection showed no significant asymmetry, and consequently there was no suspicion of publication bias.

\section{Preparation versus enemas (comparison 02.00.00)}

Of the 1210 participants in the 5 included randomised controlled trials 601 were allocated for mechanical bowel preparation (Group A), and 609 for no preparation or rectal enemas (Group B), before elective colorectal surgery.

\section{Primary outcomes}

\section{(i) Anastomotic leakage (stratified)}

\section{(a) Low anterior resection}

Seven-point-four percent of participants in Group A (8 out of 107) who had low anterior resections suffered anastomotic leakage, compared with $7.9 \%$ in Group B (7 out of 88 ); the Peto OR was 0.93 (95\% confidence interval (Cl): 0.34, 2.52 (non-significant)), and there was no statistical heterogeneity (Moral 2009; Scabini 2010; Zmora 2003).

\section{(b) Colonic surgery}

Four-point-zero percent of participants in Group A (11 out of 269) who had colonic surgery suffered anastomotic leakage, compared with $2.0 \%$ (6 out of 299) in Group B; the Peto OR was 2.15 (95\% Cl: $0.79,5.84$ (non-significant)), and there was no statistical heterogeneity (Moral 2009; Scabini 2010; Zmora 2003).

\section{(ii) Overall anastomotic leakage}

Overall anastomotic leakage was $4.4 \%$ in Group A (27 out of 601 participants), compared with 3.4\% (21 of 609 participants) in Group $\mathrm{B}$; the Peto OR was 1.32 (95\% Cl: 0.74, 2.36 (non-significant)). The chi-squared test for heterogeneity gave: $\mathrm{Chi}^{2}=4.49, \mathrm{df}=4(\mathrm{P}=0.34)$; $I^{2}=11 \%$ (Bucher 2005; Moral 2009; Platell 2006; Scabini 2010; Zmora 2003).

\section{Secondary outcomes}

\section{(iii) Mortality}

One-point-four percent of participants in Group A (9 out of 601) died, compared with $0.9 \%$ (6 out of 609) in Group B; the Peto OR was 1.47 (95\% Cl: 0.56 to 3.90 (non-significant)); there was no statistical heterogeneity (Bucher 2005; Moral 2009; Platell 2006; Scabini 2010; Zmora 2003). 


\section{(iv) Peritonitis}

Two-point-six percent of participants in Group A (16 out of 601 ) suffered peritonitis compared with $1.9 \%$ (12 of 609) in Group B; the Peto OR was 1.37 (95\% Cl: 0.64 to 2.93 (non-significant)), and there was no statistical heterogeneity (Bucher 2005; Moral 2009; Platell 2006; Scabini 2010; Zmora 2003).

\section{(v) Reoperation}

Three-point-one percent of participants in Group A (7 out of 225) required reoperation compared with $3.6 \%$ (8 out of 222) participants in Group B; the Peto OR was 0.86 (95\% Cl: 0.32 to 2.33 (non-significant)), and with no statistical heterogeneity (Bucher 2005; Platell 2006).

\section{(vi) Wound infection}

Nine-point-nine percent of participants in Group A (60 out of 601) suffered from wound infection compared with $8.0 \%$ (49 of 609 participants) in Group B; the Peto OR was 1.26 (95\% Cl: 0.85 to 1.88 (non-significant)). The chi-squared test for heterogeneity gave: $\mathrm{Chi}^{2}$ $=2.62, \mathrm{df}=4(\mathrm{P}=0.62) ; \mathrm{I}^{2}=0 \%$ (Bucher 2005; Moral 2009; Platell 2006; Scabini 2010; Zmora 2003).

\section{DISCUSSION}

At a conference in 1972 nobody took any notice when Hughes presented his trial suggesting that mechanical bowel preparation could be omitted prior to colorectal surgery (Hughes 1972). In 1987, when Irving questioned the efficacy of mechanical bowel cleansing (Irving 1987), his study was very much criticised by the editor of The British Journal of Surgery (Johnston 1987).

Results from studies on patients submitted for emergency surgery, as well as experimental trials, supported the idea of not cleansing. In 1992, an abstract of a prospective, randomised trial was published in The British Journal of Surgery that demonstrated favourable results for a group of patients who did not receive mechanical bowel preparation before elective colorectal surgery (Brownson 1992).

In the first version of this review, in which five trials were included (Brownson 1992; Burke 1994; Fillmann 1995; Miettinen 2000; Santos 1994), we could demonstrate no difference in wound infection and anastomotic leakage rates between groups of participants who received, or did not receive, mechanical bowel preparation. There was a trend suggesting that cleansing might be dangerous, but the total number of participants was too small to demonstrate any significant difference. The reviewers suggested that more trials should be conducted.

Four further trials were included in the first update; two were full papers (Tabusso 2002; Zmora 2003), and two were conference proceedings (Bucher 2005; Fa-Si-Oen 2005). Their inclusion changed the results substantially: the incidence of anastomotic leakage was statistically significantly higher in the group that had mechanical bowel preparation. Despite the results, the reviewers affirmed their point of view, that trials stratifying the site of anastomosis - colonic and colorectal - would be essential in order to enable them to give recommendations. After the publication of this update in 2005, several national guidelines changed their recommendations so that preoperative bowel cleansing was omitted for colonic surgery. However, a long way must be traversed to convert this conduct in a routine.
Five new trials were included for the second update (Contant 2007; Jung 2006; Jung 2007; Pena-Soria 2007; Ram 2005), along with the two abstracts that had originally been included in the first update and that were now published as full articles (Bucher 2005; Fa-Si-Oen 2005). A total of 14 randomised trials, including more than 4000 participants were analysed with systematic criteria. The results showed no significant difference between the groups, although a trend towards cleansing being potentially dangerous still exists. One might find it strange, that the conclusion changes over time, but this reflects the performance and inclusion of larger, and perhaps better, trials during this update period.

At this update, six more trials (Bretagnol 2010; Leiro 2008; Moral 2009; Platell 2006; Scabini 2010; Van't Sant 2010) were included, analysing a total of 5805 participants in eighteen studies.

The authors of the review chose to split into two comparisons, due to a greater number of trials submitted one group to undergo a mechanical bowel preparation and another group to cleaning the rectum with enemas in cases of rectal surgery, colorectal anastomosis.

The studies included in this new update do not provide different results, there is still no statistical difference despite the number of included patients are five times larger than the first review. The scientific quality of the newer studies are higher as the importance of allocation concealment (Schulz 1996) now is well recognised.

One of the critiques made for our review is the inclusion of studies where bowel continuity was not restored. Despite the inclusion of patients who did not undergo primary anastomosis (Fillmann 1995, Santos 1994, Tabusso 2002) and others submitted to a defunctioning stoma (Bretagnol 2010, Contant 2007, Van't Sant 2010), the sensitivity analysis showed no statistical difference: these patients were distributed equally in both groups (with and without mechanical bowel preparation).

We do not believe that the sum of more studies may change these results. An Italian ongoing study (\# NCT00940030 - Andreoni, Biffi, Bertani) must be included, when completed, at the comparison number 2 (Mechanical Bowel Preparation versus Enema).

Published studies show that the preparation is not conducive to bacterial translocation (Kale 1998; Barrera 2008), but also does not prevent anastomotic dehiscence (Bretagnol 2010; Brownson 1992; Bucher 2005; Burke 1994; Contant 2007; Fa-Si-Oen 2005; Fillmann 1995; Jung 2006; Jung 2007; Leiro 2008; Miettinen 2000; Moral 2009; Pena-Soria 2007; Platell 2006; Ram 2005; Santos 1994; Scabini 2010; Tabusso 2002; Van't Sant 2010; Zmora 2003).

Inadequate bowel cleansing, leading to liquid bowel contents, increases the rate of postoperative infectious complications (Mahajna 2005). By omitting mechanical preparation one overcomes the problems of the poorly prepared bowel. The content of the bowel (bulky stools) can be manipulated into the bowel segment to be resected, making the zone of anastomosis clear. Some authors demonstrated an association with structural alteration and inflammatory changes in the large bowel wall when submitted to mechanical cleansing, and proposed the elucidation of these changes with the septic abdominal morbidity (Bucher 2005). 
The indication of prophylactic antibiotics is unanimous among the authors of the studies included in the first publication and all the updates. It is universally accepted that antibiotic prophylaxis must be considered one of the most important measures in order to prevent infections complications in colorectal surgery. In 1981 Baum and colleagues (Baum 1981) compared the incidence of wound infection and mortality rates of patients given antimicrobial prophylaxis for colorectal surgery with controls not given antimicrobial agents. They found that the rate of wound infection was significantly higher in the control group and suggested that no study comparing antibiotic prophylaxis versus placebo should be executed.

As for rectal surgery, there is still doubt. The need for studies involving patients undergoing low anterior resection is still there. The presence of fecal content in the rectum is a condition that impairs the surgeon at the time of anastomosis? Is wash out of bowel contents at the anal site of the anastomosis sufficient? Will rectal enemas decrease the risk of anastomotic leakage? We believe that these questions remain unanswered.

The need for cleansing before laparoscopic surgery is a matter of debate too. Only three trials reported directly that laparoscopic surgery was included (Bretagnol 2010; Bucher 2005; Moral 2009), and a thorough assessment is needed. It has been argued that it is easier to do laparoscopic surgery if the bowel contains solid matter in order to be able to use gravity to get a better overview. Whether this is true, or just reflects a theoretical opinion, is unknown. The potential metabolic that follow a cleansing procedure - and that might be responsible for the potential risks of cleansing are the same, whether laparoscopic surgery is performed or not. New randomised trials are needed to determine whether or not cleansing is beneficial prior to laparoscopic surgery.

In the past, many surveys documented the methods used for mechanical bowel preparation (Beck 1990; Klauck 1993; Solla 1990). These demonstrated that all surgeons used a preoperative mechanical cleansing of the colon and some form of oral and/ or systemic antibiotics. A survey published in 2005 showed that a reasonable number of surgeons were omitting the practice of mechanical cleansing of the bowel prior to colorectal surgery (Lassen 2005). Actually several national guidelines have changed and recommending the omission of mechanical bowel preparation before elective colorectal surgery.

The dogma of the necessity of mechanical bowel preparation before elective surgery involving the colon can be broken. With the results of our systematic review, we can leave colorectal surgeons at the option of not using cleansing in any type of preparation. In cases of small tumours or the need for precise location of the lesion, being necessary to perform intraoperative colonoscopy, colon cleansing is mandatory.

\section{AUTHORS' CONCLUSIONS}

\section{Implications for practice}

Prophylactic mechanical bowel preparation prior to colonic surgery has not been proven to be valuable for patients. This review suggested that in cases of well-defined location and size of the lesion, the surgeon and his patient are free to choose. Bowel cleansing should be considered when a surgeon needs to identify pathology - for example, a small tumour - or when an intraoperative colonoscopy might be performed.

\section{Implications for research}

Regarding elective rectal surgery it is still necessary to conduct more clinical trials to address the safety and clinical effectiveness of mechanical bowel preparation compared with no preparation. Concealment of allocation is a must, especially for multicenter trials. The use of preoperative radiotherapy would need to be registered. Collaborative, properly designed, randomised controlled trials that involve a large, representative number of individuals, with explicit clinical inclusion and exclusion criteria, sufficient duration of follow up (at least 30 days after surgery), description of dropouts and withdrawals, and uniform diagnosis of all relevant outcome measures should be planned.

In laparoscopic surgery it is also necessary to conduct further clinical trials comparing mechanical bowel preparation with no preparation and mechanical bowel preparation with rectal enema.

\section{ACK N O WLEDGEMEN TS}

We want to thank the Cochrane Colorectal Cancer Group, where one of the reviewers (KFG) was in November 1999.

Sincerest thanks to Managing Editor of the CCCG, Henning $K$ Andersen, for assisting with the versions of the review. And Mrs Ina Fjeldmark for her special attention, when KFG was in Copenhagen, making everything easy and comfortable.

A special thank to Drs. Atallah and Castro and for their contribution to the development of the protocol, searches for eligible trials, and general advise.

We thank Dr Zmora, Dr Jung, Dr Santos, Dr Fillmann and Dr Pena-Soria for their politeness and attention, and for giving to us supplementary data. 


\section{R E F E R E N C E S}

\section{References to studies included in this review}

Bretagnol 2010 \{published data only\}

Bretagnol F, Panis Y, Rullier E, Rouanet P, Berdah S, Dousset B, Portier G, Benoist S, Chipponi J, Vicaut E and the French Research Group of Rectal Cancer Surgery (GRECCAR). Rectal cancer surgery with or without bowel preparation. The French Greccar III multicenter single-blinded randomised trial. Annals of Surgery 2010;252:863-868.

\section{Brownson 1992 \{published data only\}}

Brownson P, Jenkins AS, Nott D, Ellenbogen S. Mechanical bowel preparation before colorectal surgery: results of a prospective randomised trial. British Journal of Surgery. 1992; Vol. 79:461-2.

\section{Bucher 2005 \{published data only\}}

Bucher P, Gervaz P, Soravia C, Mermiollod B, Erné M, Morel P. Randomized clinical trial of mechanical bowel preparation versus no preparation before elective left-sided colorectal surgery. British Journal of Surgery 2005;92:409-14.

Burke 1994 \{published data only\}

Burke P, Mealy K, Gillen P, Joyce W, Traynor O, Hyland J. Requirement for bowel preparation in colorectal surgery. British Journal of Surgery 1994;81:907-10.

\section{Contant 2007 \{published data only\}}

Contant CME, Hop WCJ, Van't Sant HP, Oostvogel HJM, Smeets HJ, Stassen LPS, et al. Mechanical bowel preparation for elective colorectal surgery: a multicenter randomised trial. Lancet 2007;370:2112-7.

\section{Fa-Si-Oen 2005 \{published data only\}}

Fa-Si-Oen P, Roumen R, Buitenweg JA, van de Velde C, van Geldere D, Putter H, Verwaest C, Verhoef L, Waard JW, Swank D, D'Hoore A, van Uchelen FC. Mechanical bowel preparation or not? Outcome of a multicenter, randomised trial in elective open colon surgery. Diseases of the colon and rectum 2005;48:1509-16.

Fillmann 1995 \{published and unpublished data\}

* Fillmann EEP, Fillmann HS, Fillmann LS. Elective colorectal surgery without preparation [Cirurgia colorretal eletiva sem preparo]. Revista Brasileira de Coloproctologia 1995;15(2):70-1.

Fillmann HS, Fillmann LS. Elective colorectal surgery without preparation [Ciurugia colorretal eletiva sem preparo]. Conference proceedings. São Paulo, 1995.

\section{Jung 2006 \{unpublished data only\}}

Jung, B. Mechanical bowel preparation for rectal surgery. Personal communication December 2006.

\section{Jung 2007 \{published and unpublished data\}}

Jung B, Pahlman L, Nyström PO, Nilsson E for the Mechanical Bowel Preparation Study Group. Multicentre randomised clinical trial of mechanical bowel preparation in elective colonic surgery. British Journal of Surgery 2007;94:689-95.
Leiro 2008 \{published data only\}

Leiro F, Barredo C, Latif J, Martin JR, Covaro J, Brizuela G, Mospane C. Mechanical preparation in elective colorectal surgery [Preparación mecánica en cirurgía electiva del colon y recto]. Revista Argentina de Cirurgia 2008;95(3-4):154-167.

\section{Miettinen 2000 \{published data only\}}

Miettinen P, Laitinen S, Makela J, Paakkonen M. Bowel preparation is unnecessary in elective open colorectal surgery. A prospective, randomised study. Digestion supplement no. 3. Vienna, 1998. [GaPP0165]

* Miettinen RPJ, Laitinen ST, Makela JT, Paakkonen ME. Bowel preparation with oral polyethylene glycol electrolyte solution vs. no preparation in elective open colorectal surgery. Diseases of the colon and rectum 2000;43(5):669-77.

\section{Moral 2009 \{published data only\}}

Moral MA, Aracil XS, Juncá JB, López LM, Tavira RH, Garnica IA, Rodriguez OA, Soto SN. A prospective, randomised, controlled study on the need to mechanically prepare the colon in scheduled colorectal surgery [Estudio prospectivo controlado y aleatorizado sobre la necesidad de la preparación mecánica de colon en la cirurgía programada colorrectal]. Cirurgía Española 2009;85(1):20-25

\section{Pena-Soria 2007 \{published data only\}}

Pena-Soria MJ, Mayol JM, Anula R, Arbeo-Escobar A, FernandezRepresa JA. Mechanical bowel preparation influences the outcomes of elective colorectal resection with primary anastomosis by a single surgeon: intermediate analysis of a prospective single-blinded randomised trial. The Society for Surgery of the Alimentary Tract. 2006.

* Pena-Soria MJ, Mayol JM, Anula-Fernandez R, Arbeo-Escolar A, Ferrnandez-Represa JA. Mechanical bowel preparation for elective colorectal surgery with primary intraperitoneal anastomosis by a single surgeon: interim analysis of a prospective single-blinded randomised trial. Journal of Gastrointestinal Surgery 2007;11:562-7.

\section{Platell 2006 \{published data only\}}

Platell C, Barwood N, Makin G. Randomized clinical trial of bowel preparation with a single phosphate enema or polyethylene glycol before elective colorectal surgery. British Journal of Surgery 2006;93:427-33.

\section{Ram 2005 \{published data only\}}

Ram E, Sherman Y, Weil R, Vishne T, Kravarusic D, Dreznik Z. Is mechanical bowel preparation mandatory for elective colon surgery. Archives of Surgery 2005;140:285-8.

Santos 1994 \{published and unpublished data\}

Santos JCM Jr, Batista J, Sirimarco MT, Guimarães AS, Levy CE. Prospective randomised trial of mechanical bowel preparation in patients undergoing elective colorectal surgery. British Journal of Surgery 1994;81:1673-6. 
Scabini 2010 \{published data only\}

Scabini S, Rimini E, Romairone E, Scordamaglia R, Damiani G, Pertile D, Ferrando V. Colon and rectal surgery for cancer without mechanical bowel preparation: one-centre randomised prospective trial. Would Journal of Surgical Oncology 2010;8:35-39.

\section{Tabusso 2002 \{published data only\}}

Tabusso FY, Zapata JC, Espinoza FB, Meza EP, Figueroa ER. Mechanical preparation in elective colorectal surgery, a useful practice or need? [Preparación mecánica en cirurgía electiva colo-rectal, costumbre o necesidad?]. Revista de Gastroenterologia del Peru 2002;22(2):152-8.

Van't Sant 2010 \{published data only\} van't Sant HP, Weidema WF, Hop WCJ, Oostvogel HJM, Contant CME. The influence of mechanical bowel preparation in elective lower colorectal surgery. Annals of Surgery 2010;251(1):59-63.

\section{Zmora 2003 \{published and unpublished data\}}

Zmora O, Mahajna A, Bar-Zakai B, Hershko D, Shabtai M, Krausz MM, et al. Is mechanical bowel preparation mandatory for left-sided colonic anastomosis? Results of a prospective randomised trial. Techniques in Coloproctology 2006;10:131-5.

* Zmora O, Mahajna A, Bar-Zakai B, Rosin D, Hershko D, Shabtai M, et al. Colon and rectal surgery without mechanical bowel preparation. A randomised prospective trial. Annals of Surgery 2003;237:363-7.

Zmora O, Mahajna A, Bar-Zakai B, Rosin D, Hershko D, Shabtai M, et al. Left-side anastomosis without mechanical bowel preparation: a randomised, prospective trial.. Diseases of Colon and Rectum 2002; Vol. 45, issue 4:A7-A8.

\section{References to studies excluded from this review}

\section{Bretagnol 2007 \{published data only\}}

Bretagnol F, Alves A, Ricci A, Valleur P, Panis Y. Rectal cancer surgery without mechanical bowel preparation. British Journal of Surgery 2007;94:1266-71.

\section{Dorudi 1990 \{published data only\}}

Dorudi S, Wilson NM, Heddle RM. [Primary restorative colectomy in malignant left-sided large bowel obstruction]. Annals of the Royal College of Surgeons of England 1990;72:393-5.

\section{Duthie 1990 \{published data only\}}

Duthie GS, Foster ME, Price-Thomas JM, Leaper DJ. Bowel preparation or not for elective colorectal surgery. Journal of the Royal College of Surgeons of Edinburgh 1990;35:169-71.

\section{Hughes 1972 \{published data only\}}

Hughes ESR. Asepsis in large-bowel surgery. Annals of the Royal College of Surgeons of England 1972;51:347-56.
Irving 1987 \{published data only\}

Irving AD, Scrimgeour D. Mechanical bowel preparation for colonic resection and anastomosis. British Journal of Surgery 1987;74:580-1.

\section{Matheson 1978 \{published data only\}}

Matheson DM, Arabi Y, Baxter-Smith D, Alexander-Williams J, Keighley MRB. Randomized multicenter trial of oral bowel preparation and microbials for elective colorectal operations. British Journal of Surgery 1978;65(9):597-600.

\section{Memon 1997 \{published data only\}}

Memon MA, Devine J, Freeney J, From SG. Is mechanical bowel preparation really necessary for elective left sided colon and rectal surgery?. International Journal of Colorectal Disease 1997;12:298-302.

\section{References to ongoing studies}

Andreoni, Biffi, Bertani \{unpublished data only\}

Effect of Mechanical Bowel Preparation With Polyethylene Glycol Plus Bowel Enema (Glycerine 5\%) vs Bowel Enema Alone in Patients Candidates to Colorectal Resection for Malignancy. Prospective, Randomized Clinical Trial. Ongoing study October 2007.

\section{Additional references}

\section{Barrera 2008}

Barrera EA, Peñaloza MP, Bannura CG, Zúñiga TC, Contreras PJ, Cumsille GMA, Cid BH. Bowel wall alterations associated with mechanical bowel cleansing before elective colonic surgery [Alteraciones histológicas asociadas a la preparación mecánica en cirugía colorrectal electiva]. Revista Chilena de Cirurgia 2008;60(1):46-50.

\section{Baum 1981}

Baum ML, Anish DS, Chalmers TC, Sacks HS, Smith $\mathrm{H}$ Jr, Fagerstrom RM. A survey of clinical trials of antibiotic prophylaxis in colon surgery: evidence against further use of no-treatment controls. New England Journal of Medicine 1981;305:795-9.

\section{Beck 1990}

Beck DE, Fazio VW. Current preoperative bowel cleansing methods. Diseases of the colon and rectum 1990;33:12-5.

\section{Chung 1979}

Chung RS, Gurll NJ, Berglund EM. A controlled trial of whole gut lavage as a method of bowel preparation for colonic operations. American Journal of Surgery 1979;137:75-81.

\section{Clarke 1977}

Clarke JS, Condon RE, Bartlett JG, Gorbach SL, Nichols RL, Ochi S. Preoperative oral antibiotics reduce septic complications of colon operations: results of prospective, randomised, double-blind clinical study. Annals of Surgery 1977;186(3):251-9. 


\section{Goligher 1970}

Goligher JC, Graham NG, De Dombal FT. Anastomotic dehiscence after anterior resection of rectum and sigmoid. British Journal of Surgery 1970;57(2):109-18.

\section{Grabham 1995}

Grabham JA, Moran BJ, Lane RHS. Defunctiong colostomy for low anterior resection: a selective approach. British Journal of Surgery 1995;82:1331-2.

\section{Halsted 1887}

Halsted WS. Circular suture of the intestine: an experimental study. The American Journal of the Medical Sciences 1887;94:436-61.

\section{Higgins 2008}

Higgins JPT, Green S (editors). Cochrane Handbook for Systematic Reviews of Interventions Version 5.0.0 [updated February 2008]. Available from www.cochrane-handbook.org. Chicester: Wiley \& Blackwell Publishers, 2008.

\section{Johnston 1987}

Johnston D. Bowel preparation for colorectal surgery [editorial]. British Journal of Surgery 1987;74:553-4.

\section{Kale 1998}

Kale TI, Kuzu MA, Tekeli A, Tanik A, Aksoy M, Cete M. Aggressive bowel preparation does not enhance bacterial translocation, provided the mucosal barrier is not disrupted: a prospective, randomised study. Disease of Colon and Rectum 1998;41(5):636-41.

\section{Klauck 1993}

Klauck HB, Szpacenkopf D, Fayad JB, Moreira CEL, Sá MA, Coutinho JR. Methods of mechanical bowel preparation in elective colonic surgeries. A national survey [Métodos de preparo de cólon em cirurgias eletivas - Resultado de um levantamento nacional]. Revista Brasileira de Coloproctologia 1993;13(2):46-50.

\section{Lassen 2005}

Lassen K, Hannemann P, Ljungqvist O, Fearon K, Dejong CHC, von Meyenfeldt MF, et al. Patterns in current preoperative practice: survey of colorectal surgeons in five northern European countries. British Medical Journal 2005;330:1420-1.

\section{Mahajna 2005}

Mahajna A, Krausz M, Rosin D, Shabtai M, Hershko D, Ayalon A, et al. Bowel preparation is associated with spillage of bowel contents in colorectal surgery. Diseases of the colon and rectum 2005;48:1626-31.

\section{Mealy 1992}

Mealy K, Burke P, Hyland J. Anterior resection without a defunctioning colostomy: questions of safety. British Journal of Surgery 1992;79:305-7.

\section{Nichols 1971}

Nichols RL, Condon RE. Preoperative preparation of the colon. Surgery, Gynecology \& Obstetrics 1971;132(2):323-37.

\section{O' Dwyer 1989}

O' Dwyer PJ, Conway W, McDermott EWM, O' Higgins NJ. Effect of mechanical bowel preparation on anastomotic integrity following low anterior resection in dogs. British Journal of Surgery 1989;76:756-8.

\section{Platell 1998}

Platell C, Hall J. What is the role of mechanical bowel preparation in patients undergoing colorectal surgery?. Diseases of the colon and rectum 1998;41:875-82.

\section{Schein 1995}

Schein M, Assalia A, Eldar S, Wittmann DH. Is mechanical bowel preparation necessary before primary colonic anastomosis?. Diseases of the colon and rectum 1995;38:749-54.

\section{Schulz 1996}

Schulz KF, Grimes DA, Altman DG, Hayes RJ. Blinding and exclusions after allocation in randomised controlled trials: survey of published parallel group trials in obstetrics and gynaecology. BMJ 1996;312:742-4.

\section{Slim 2004}

Slim K, Vicaut E, Panis Y, Chipponi J. Meta-analysis of randomised clinical trials of colorectal surgery with or without mechanical bowel preparation. British Journal of Surgery 2004;91:1125-30.

\section{Smith 1983}

Smith SR, Connolly JC, Gilmore OJ. The effect of faecal loading on colonic anastomotic healing. British Journal of Surgery 1983;70:49-50.

\section{Solla 1990}

Solla JA, Rothenberger DA. Preoperative bowel preparation. A survey of colon and rectum surgeons. Diseases of the colon and rectum 1990;33:154-9.

\section{Thornton 1997}

Thornton FJ, Barbul A. Healing in the gastrointestinal surgery. Surgical Clinics of North America 1997;77(3):549-73.

\section{van Geldere 2002}

van Geldere D, Fa-Si-Oen P, Noach LA, Rietra PJ, Peterse JL, Boom RP. Complications after colorectal surgery without mechanical bowel preparation. Journal of the American College Surgeons 2002;194(1):40-7.

\section{Wille-Jørgensen 1999}

Wille-Jørgensen P, Kronborg O, Simon N, Munro A, McLeod R, Nelson R [editors]. Colorectal Cancer Group's Module of the Cochrane Database of Systematic Reviews. The Cochrane Library [database on disk and CD-ROM]. Oxford: Update Software, 1999, issue Issue 4.

\section{References to other published versions of this review Guenaga 2002}

Guenaga KF. Preoperative bowel cleansing. Seminars in Colon \& Rectal Surgery 2002;13:53-61. 


\section{Guenaga 2003}

Guenaga KF, Matos D, Castro AA, Atallah AN, Wille-Jørgensen P. Mechanical bowel preparation for elective colorectal surgery. Cochrane Database of Systematic Reviews 2003, Issue 2. [DOI: 10.1002/14651858.CD001544.pub3]

\section{Guenaga 2005}

Guenaga KF, Matos D, Castro AA, Atallah AN, Wille-Jørgensen P. Mechanical bowel preparation for elective colorectal surgery. Cochrane Database of Systematic Reviews 2005, Issue 1. [DOI: 10.1002/14651858.CD001544.pub2]

\section{Guenaga 2009}

Guenaga KF, Matos D, Castro AA, Atallah AN, Wille-Jørgensen P. Mechanical bowel preparation for elective colorectal surgery.

\section{CHARACTERISTICS OF STUDIES}

Characteristics of included studies [ordered by study ID]
Cochrane Database of Systematic Reviews 2009, Issue 1. [DOI: 10.1002/14651858.CD001544.pub2]

\section{Wille-Jorgensen 2003}

Wille-Jorgensen P, Guenaga KF, Castro AA, Matos D. Clinical value of preoperative mechanical bowel cleansing in elective colorectal surgery: a systematic review. Diseases of the colon and rectum 2003;46:1013-20.

\section{Wille-Jorgensen 2005}

Wille-Jorgensen P, Guenaga KF, Matos D, Castro AA. Preoperative mechanical bowel cleansing or not? an update metaanalysis. Colorectal Disease 2005;7:304-310.

* Indicates the major publication for the study

\section{Bretagnol 2010}

Methods

Randomisation was performed centrally via an interactive voice randomisation system.

Single-blinded: the surgeon was blinded to the randomisation process and the preparation status of all patients.

Withdrawal/dropout:7 patients were excluded (5 missing consent form, 1 refusal of surgical treatment, 1 loss of follow-up).

Follow-up: 30 days postoperative.

Participants Inclusion criteria: all the patients aged 18 years or old with rectal cancer who underwent laparoscopic or open elective rectal resection with mesorectal excision and sphincter preservation.

Exclusion criteria: very low tumours (abdominal perineal excision): metastasis in the liver or lungs; T4 rectal cancer; synchronous adenocarcinoma; and/or gastrointestinal disease, refusing extensive colonic surgery.

Diseases: rectal cancer.

Number of participants: 178 (102 male; 76 female).

Age: 54 - 71 years.

Location of study: 8 french hospitals (Paris (2 hospitals), Bordeaux, Montpellier, Marseilles, Toulouse, Boulogne Billancourt, Clermont-Ferrand).

Antibiotics: $500 \mathrm{mg}$ of metronidazole $+1 \mathrm{~g}$ of ceftriaxone at anaesthetic induction and were continued every 2 hours during the surgical procedure.

Interventions

Group A - MBP $(n=89)$ : oral laxatives and retrograde enemas - senna solution. After the preparation diet was confined to clear fluids.

Group B - no MBP ( $n=89)$ : no preoperative dietary restrictions.

Anastomotic leakage: Group A = 8, Group B - 17
- Asymptomatic anastomotic leakage: Group A = 2, Group B = 3;
- Clinical anastomotic leakage: Group A = 6, Group B = 14.
Wound abscess: Group A = 3, Group B = 1.


Pelvic abscess: Group A = 1, Group B = 7 .

Peritonitis: Group A = 2, Group B $=6$.

Reoperation: Group A = 12, Group B = 5 .

Infectious abdominal complications: Group A = 15, Group B = 34 .

Infectious extra abdominal complications: Group A = 1, Group B = 1 .

Non infectious abdominal complications: Group $A=7$, Group $B=14$.

Non infectious extra abdominal complications: Group A = 5, Group B $=1$.

Necessity to rectal stump washout intra operatively for pool preparation: Group A = 43, Group B $=47$.

Intraoperative faecal spillage: Group A = 2, Group B = 7 .

Notes

A multicenter study: 8 participating national (France) hospitals.

Included patients with preoperative radiotherapy and chemiotherapy.

Intention-to-treat analysis was performed.

The sample size was calculated ( $\mathrm{n}=90$ participants, in each group).

Temporaly ileostomy: Group A = 71, Group B = 74 .

\section{Risk of bias}

\begin{tabular}{lll}
\hline Bias & Authors' judgement & Support for judgement \\
\hline $\begin{array}{l}\text { Allocation concealment } \\
\text { (selection bias) }\end{array}$ & Low risk & A - Adequate \\
\hline
\end{tabular}

Brownson 1992

Methods Stated that randomised, but no details provided about randomisation method.

Participants Inclusion criteria: participants undergoing elective colorectal surgery.

Exclusion criteria: no details.

Diseases: colorectal cancer: 164/179; other: 14/179.

Number of participants: 179.

Age: no details.

Location of study: Liverpool, UK.

\begin{tabular}{ll}
\hline Interventions & Group A - MPB $(\mathrm{n}=86) ;$ \\
& Group B - no preparation $(\mathrm{n}=93)$. \\
& Antibiotics: perioperative intravenous (no more details).
\end{tabular}

Outcomes Wound infection: Group A = 5, Group B = 7 .

Intra-abdominal sepsis: Group $A=8$, Group $B=2$.

Anastomic leakage: Group A $=8 / 67^{\star}$, Group B $=1 / 67^{\star}$.

*only participants in whom bowel continuity was restored. 
Brownson 1992 (Continued)

Attempt to contact the authors met with no success.

\section{Risk of bias}

\begin{tabular}{lll}
\hline Bias & Authors' judgement & Support for judgement \\
\hline $\begin{array}{l}\text { Allocation concealment } \\
\text { (selection bias) }\end{array}$ & Unclear risk & B - Unclear \\
\hline
\end{tabular}

\section{Bucher 2005}

\begin{tabular}{ll} 
Methods & Randomisation: computer-generated. \\
& Blinding: not described. \\
& Withdrawal/dropouts: all participants finished the study. \\
& Follow up: 30 days after surgery. \\
\hline Participants & Inclusion criteria: elective left-sided colorectal surgery; participants aged 18 years or more; no MBP or \\
antibiotics the week before inclusion. \\
Exclusion criteria: any patient who could not tolerate the preparation; those who have had the bowel \\
"prepared" for another procedure within the previous week; immunosuppression; human immunodefi- \\
ciency virus infection; liver cirrhosis; and tumours smaller than 2 cm. \\
Diseases: colorectal cancer, diverticular disease, Hartmann's reversal, adenoma, endometriosis. \\
Number: 153 (81 male; 72 female). \\
Age: 63 years (21-92 years). \\
Location: two affiliated departments in Geneva and Yverdon (Switzerland). \\
Date: $2001-2003$. \\
Antibiotics: metronidazole and ceftriaxone (continued 24 h after surgery).
\end{tabular}

Interventions

Group A - MBP ( $n=78)$ : 3 litres PEG 12-16 h before surgery.

Group B - no preparation $(n=75)$.

Note: one $250 \mathrm{ml}$ saline enema before surgery to participants undergoing anterior resection of the rectum.

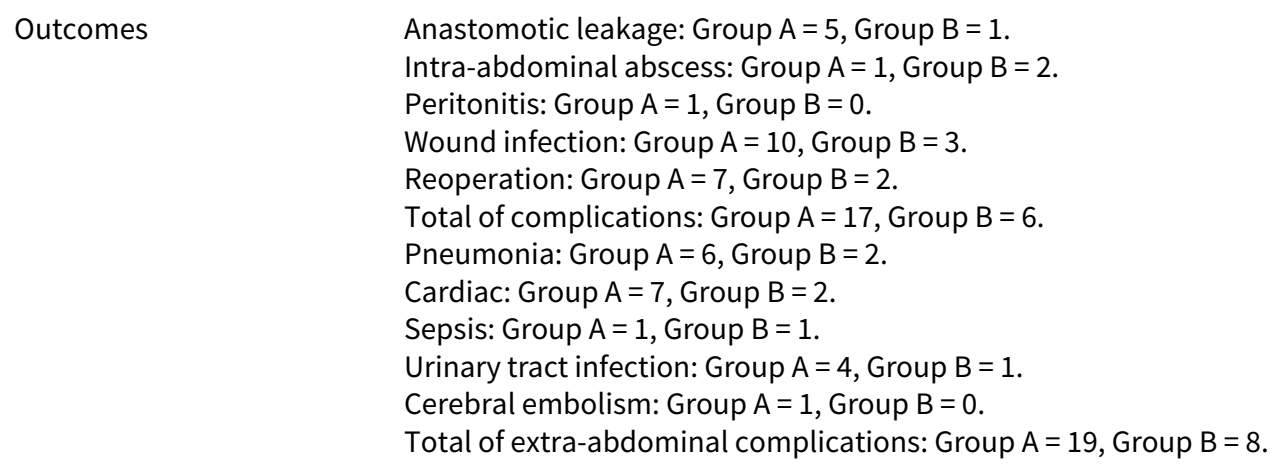

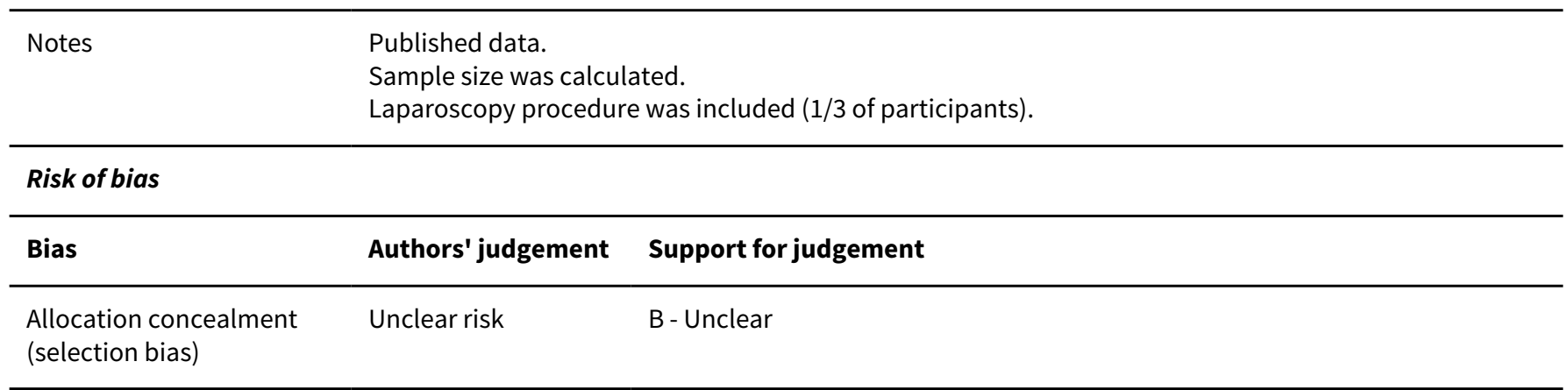


Burke 1994

Methods

Stated that randomised, but no details provided about randomisation method.

Blinding: single-blind: surgeons were aware of participants' bowel preparation.

Withdrawal/dropout: $31 \%$ withdrew (17/186), there were no dropouts.

Follow up: not related.

On a day 7 before surgery, the colorectal anastomosis was checked, in the first half of the series.

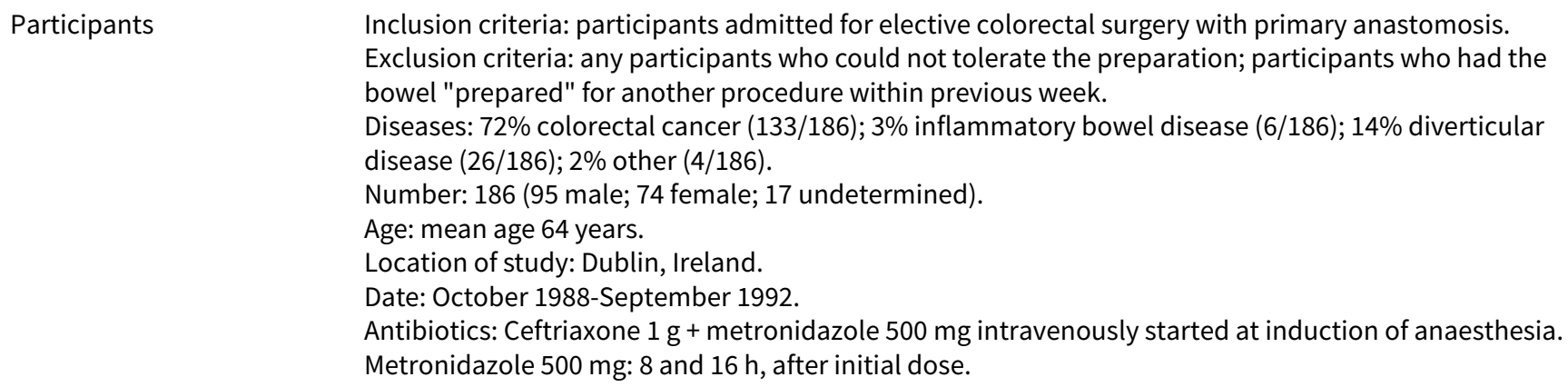

Interventions Group A - MBP group $(n=82)$ : sodium picosulphate $10 \mathrm{mg}$, the day before surgery (dose in morning and afternoon).

Group B - normal diet and no other bowel preparation $(n=87)$.

$\begin{array}{ll}\text { Outcomes } & \text { Death: Group A =2; Group B =0. } \\ & \text { Cardiorespiratory complications: Group A = 8; Group B = } 9 . \\ & \text { Wound infection: Group A }=4 ; \text { Group B }=3 . \\ & \text { Anastomotic dehiscence: Group A }=3 ; \text { Group B }=4 . \\ & \text { Reoperation: Group A }=2 ; \text { Group B }=4 .\end{array}$

Notes Representative sample: consecutive participants.

Surgical procedures that were excluded: participants submitted to Hartman's resection (Group A = 5: Group $B=5$ ); defunctioning colostomy (Group $A=0$ : Group $B=2$ ); abdominal excision of the rectum (Group $A=1$ : Group $B=2$ ); coloanal anastomosis with colostomy (Group A = 0: Group B =1); colostomy for rectal polyp (Group A = 1: Group B =0).

All surgery was performed by one of two consultant surgeons or a senior registrar.

Participants without anastomosis were excluded.

The outcome "Anastomotic leakage" was stratified, by the author:

Left colectomy: Group A = 43; Group B = 51 .

Anterior resection: Group A = 39; Group B $=36$.

Anastomotic leakage/low anterior resection: Group A =3/39; Group B =4/36.

\section{Risk of bias}

Bias Authors' judgement Support for judgement

Allocation concealment Unclear risk B - Unclear

(selection bias)

\section{Contant 2007}

Methods

Randomisation: computer-generated randomisation list; participants were allocated to each intervention by means of numbered sealed envelopes that corresponded to the randomisation list.

Blinding: none. 
Withdrawal/dropouts: 77 participants excluded.

Follow up: 24 days (17 - 34 days).

Inclusion criteria: indication for elective colorectal surgery with primary anastomosis.
Exclusion criteria: acute laparotomy; laparoscopic colorectal surgery; contraindication for MBP; ileal
stoma; younger than 18 years.
Diseases: colorectal cancer, inflammatory bowel disease, radiation induced stenosis, endometriosis,
correction of Hartmann's.
Number: 1354 ( 682 male, 672 female).
Age: mean age 67 years.
Location of study: 13 participating hospitals in the Netherlands.
Date: April 1998-February 2004 .
Antibiotics: according to the guideline of each hospital: cefuroxime + metronidazole, cefazolin +
metronidazole, cefamandole + metronidazole, gentamycin + metronidazole, amoxicillin + clavulanate,
and others.

Interventions

Group A - MBP ( $n=670):$ PEG + bisacodyl (11 hospitals) or sodium phosphate solution (2 hospitals); fluid diet on the day before surgery.

Group B - normal meals $(n=684)$.

Outcomes

Anastomotic leakage: Group A = 32, Group B $=37$.

Wound infection: Group $A=90$, Group $B=96$.

Fascia dehiscence: Group A = 19, Group B $=16$.

Urinary tract infection: Group $A=71$, Group $B=70$.

Pneumonia: Group A = 39, Group B = 51.

Intra-abdominal abscess: Group A = 15, Group B $=32$.

Secondary intervention (reoperation): Group $A=58$, Group $B=58$.

Mortality: Group A = 20, Group B = 26.

Outcomes measured in days (postoperatives):

Hospital stay: Group A = 10, Group B $=10$.

Resumption of normal diet: Group A =6, Group B $=6$.

No postoperative complications: Group A $=462$, Group B $=452$.

Notes A multicenter study.

Sample size was calculated.

By chance, more participants who smoked and had inflammatory bowel disease were allocated to MBP group.

$\mathrm{X}^{2}$ test or Fischer's exact test to compare complication rates between groups; Mann-Whitney test to compare continuous or graded outcomes.

Univariate analysis to asses the risk of anastomotic leakage. Multivariated logistic regression to test the risk factors simultaneously for any association with anastomotic failure. Multivariate analysis stowed that ASA classification, type of anastomosis and blood loss during operation were independent risk factors for anastomotic leakage.

In 2010 subgroup analysis is published by van't Sant the authors of this review made the calculus:

Colonic surgery $(n=905)$ : Group A = 434; Group B $=471$.

- Anastomotic leakage: Group A = 14; Group B = 23.

\section{Risk of bias}

\section{Bias}

Authors' judgement Support for judgement 
Contant 2007 (Continued)
Allocation concealment
Low risk
A - Adequate
(selection bias)

\section{Fa-Si-Oen 2005}

$\begin{array}{ll}\text { Methods } & \text { Central trial office of randomisation, computer generated. } \\ \text { Concealment OK. } \\ \text { Blinding: not described. } \\ \text { Withdrawal/dropout: no exclusions. } \\ \text { Follow up: } 3 \text { months. }\end{array}$

Inclusion criteria: elective colon surgery.
Exclusion criteria: previous radiotherapy and/or chemotherapy; idiopathic inflammatory bowel dis-
ease; obstructive tumours; emergency laparotomy; MBP one week before the surgery; ileocaecal resec-
tions and resections below the peritoneal reflection.
Diseases: recurrent diverticular disease, colon malignancy, other.
Number: 250 (114 male; 136 female).
Age: $27.7-89.0$ years.
Location: 5 centres in the Netherlands (4) and Belgium $(1)$.
Date: 1 October $1998-1$ October 2002.
Antibiotics: cefazolin $(2 \mathrm{~g})+$ metronidazole $(1.5 \mathrm{~g})$ or gentamicin $(240 \mathrm{mg})+$ metronidazole $(1.5 \mathrm{~g}), 30$
minutes before surgery.

$\begin{array}{ll}\text { Interventions } & \text { Group A - MBP }(n=125): 4 \text { litres of PEG. } \\ \text { Group B - normal meal up to ten hours before surgery }(n=125) .\end{array}$

\begin{tabular}{ll}
\hline Outcomes & Anastomotic leakage: Group $A=7$, Group $B=6 ;$ \\
& Wound infection: Group $A=9$, Group $B=7$. \\
& Reoperation: Group $A=13$, Group $B=11$. \\
\hline Notes & Primary data. \\
& Multicentre study. \\
& Sample size was calculated. \\
& All participants were included as intention to treat.
\end{tabular}

\section{Risk of bias}

\begin{tabular}{lll}
\hline Bias & Authors' judgement & Support for judgement \\
\hline $\begin{array}{l}\text { Allocation concealment } \\
\text { (selection bias) }\end{array}$ & Low risk & A - Adequate \\
\hline
\end{tabular}

\section{Fillmann 1995}

\begin{tabular}{ll}
\hline Methods & Randomisation: no details. \\
Blinding: double-blind (orange juice for the control group; no details about blinding the surgeons). \\
Withdrawals/dropouts: no withdrawals or dropouts. \\
Follow up: 30 days after surgery. \\
\hline Participants \\
$\begin{array}{l}\text { Inclusion criteria: participants admitted for elective colorectal surgery with primary anastomosis. } \\
\text { Exclusion criteria: no exclusions. } \\
\text { Diseases (Group A/B): colorectal cancer }(22 / 21) \text {; diverticular disease (5/6); inflammatory bowel disease }\end{array}$
\end{tabular}


Fillmann 1995 (Continued)

Number: 60 (33 male; 27 female).

Age: $31-82$ years.

Location: Porto Alegre, RS, Brazil.

Date: 1992-1993.

Antibiotics: metronidazole + gentamicin $1 \mathrm{~h}$ before surgery, and then for $48 \mathrm{~h}$.

$\begin{array}{ll}\text { Interventions } & \text { Group A - MBP }(n=30): 500 \mathrm{ml} \text { mannitol } 20 \%+500 \mathrm{ml} \text { orange juice. } \\ \text { Group B - orange juice }(n=30) .\end{array}$

\begin{tabular}{|c|c|}
\hline Outcomes & 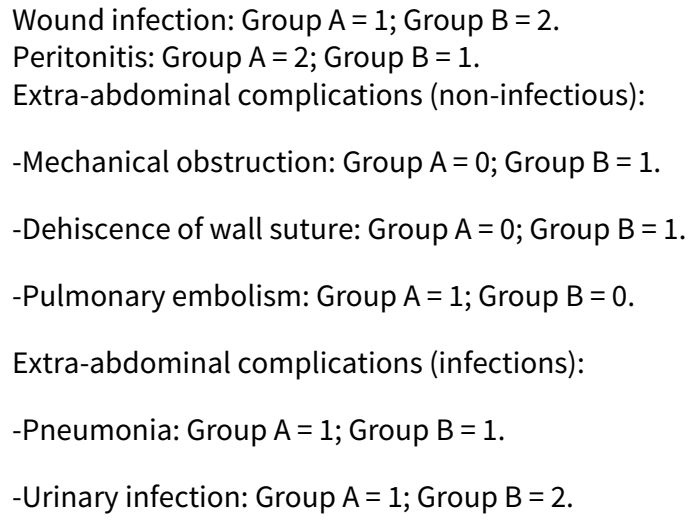 \\
\hline Notes & $\begin{array}{l}\text { The sample size was calculated, but no details given. } \\
\text { Included participants without anastomosis. } \\
\text { Recurrence was not mentioned. } \\
\text { No deaths in this trial. }\end{array}$ \\
\hline
\end{tabular}

\section{Risk of bias}

\begin{tabular}{lll}
\hline Bias & Authors' judgement & Support for judgement \\
\hline $\begin{array}{l}\text { Allocation concealment } \\
\text { (selection bias) }\end{array}$ & Low risk & A-Adequate \\
\hline
\end{tabular}

\section{Jung 2006}

$\begin{array}{ll}\text { Methods } & \text { Randomisation: Central randomisation; random numbers. } \\ & \text { Blinding: none. }\end{array}$
Participants Inclusion criteria: participants undergoing elective open surgery for cancer, adenoma or diverticular disease of the rectum, involving an anastomosis; aged between 18-85 years with an ASA grade of I, II or III.
Exclusion criteria: laparoscopic surgery; procedures involving a stoma; ASA scope IV and a life ex- pectancy of less than 6 months.
Diseases: cancer, adenomas, diverticular disease.
Number: 44.
Date: January 1999-March 2005.
Antibiotics: oral sulphamethoxazole-trimethoprim + metronidazole, cephalosporin + metronidazole, or doxycycline + metronidazole.

\section{Outcomes}


Jung 2006 (Continued)

General infections: Group A = 5, Group B $=1$.

Notes A multicenter study.

Surgeons in this study were all specialists in colorectal surgery.

Intention-to-treat analysis.

This is a group of participants, who were first included in Jung 2007, but later excluded due to rectal

surgery. These data are unpublished thus far.

\section{Risk of bias}

\section{Bias}

Authors' judgement Support for judgement

Allocation concealment
(selection bias)

Jung 2007

$\begin{array}{ll}\text { Methods } & \text { Randomisation: central randomisation; random numbers. } \\ & \text { Blinding: none. } \\ & \text { Withdrawal/dropout: } 14 \text { (Group A), } 12 \text { (Group B): lost to follow up and data not submitted. } \\ & \text { Follow up: } 30 \text { days after surgery. }\end{array}$
Participants Inclusion criteria: participants undergoing elective open surgery for cancer, adenoma or diverticular disease of the colon, involving an anastomosis; aged between 18-85 years with an ASA grade of I, II or III.
Exclusion criteria (162 excluded): laparoscopic surgery; procedures involving a stoma; ASA scope IV and a life expectancy of less than 6 months.
Diseases: cancer, adenomas, diverticular disease.
Number: 1343 (623 male; 720 female)
Age: 69 years (28-86 years).
Location of study: 1 German and 20 Swedish colorectal units.
Date: January 1999-March 2005.
Antibiotics: oral sulphamethoxazole-trimethoprim + metronidazole (46\%); cephalosporin + metronida- zole (33\%); doxycycline + metronidazole (14\%).

Interventions $\quad$ Group A - MBP $(n=686)$ : PEG or sodium phosphate.

Group B - no preparation $(n=657)$.

Outcomes

Anastomotic dehiscence: Group A = 13, Group B $=17$.

Wound infection: Group $A=54$, Group $B=42$.

Deep abscess: Group A = 5, Group B $=11$.

Reoperation: Group A = 30, Group B = 35 .

Wound disruption: Group A = 10, Group B $=13$.

Cardiovascular complications: Group $A=35$, Group $B=30$.

General infections: Group A = 54, Group B $=45$.

Surgical site: Group A = 103, Group B = 106 .

Total number of complications: Group A = 192, Group B $=181$.

Notes A multicenter study.

The groups were well matched with regard to age, sex and diagnosis.

Surgeons in this study were all specialists in colorectal surgery.

Intention-to-treat analysis.

The sample size was calculated.

The mean hospital stay was 9 days (7-14 days).

Extra data after stratification has been obtained in a personal communication with the author. 
Jung 2007 (Continued)

Risk of bias

\begin{tabular}{lll}
\hline Bias & Authors' judgement & Support for judgement \\
\hline $\begin{array}{l}\text { Allocation concealment } \\
\text { (selection bias) }\end{array}$ & Low risk & A - Adequate \\
\hline
\end{tabular}

Leiro 2008

Methods

Randomisation: sealed envelopes at the time of the assignment of the surgical date.

Blinding: not described.

Withdrawal/Dropout: not described.

Duration of follow-up: not related.

Participants Inclusion criteria: all the consecutives electives surgeries with colonic anastomosis (ileocolonic, colonic, colorectal), including colonic transit reestablishment.

Exclusion criteria: patients with immediately postoperative death without relation an intraabdominal sepsis or anastomotic leakage; patients whom refused to be operated without mechanical bowel preparation; patients submitted to bowel preparation for colonoscopy within 4 days prior to surgery.

Diseases: benign or malignant colorectal pathology.

Number of participants: 129 (77 male; 52 female).

Age: 15 - 85 years.

Location of study: Hospital General de Agudos and private clinic, Lanus, province of Buenos Aires.

Time os study: 2005 (March) - 2006 (September).

Antibiotics: ciprofloxacin $500 \mathrm{mg}+$ metronidazole $500 \mathrm{mg}$.

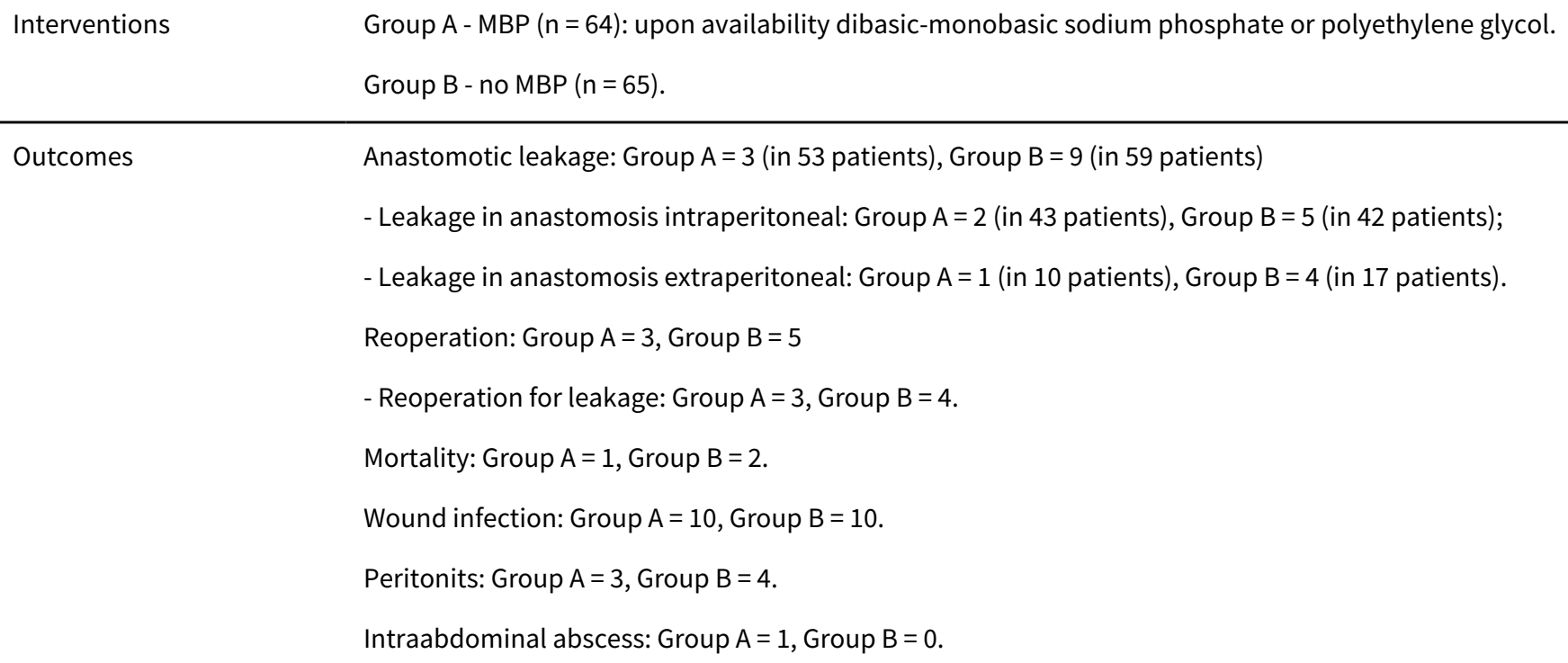


Leiro 2008 (Continued)

Patients without anastomosis: Group A $=6$ abdominoperineal amputation, 5 Hartmann's procedure; Group B $=4$ abdominoperineal amputation, 2 Hartmann's procedure.

Anastomosis and dehiscence:

- Right: Group A (25) = 1, Group B (21) = 2;

- Left: Group A (18) = 1, Group B (21) = 2;

- Low: Group A (10) = 1, Group B (17) = 4 .

\section{Risk of bias}

\begin{tabular}{lll}
\hline Bias & Authors' judgement & Support for judgement \\
\hline $\begin{array}{l}\text { Allocation concealment } \\
\text { (selection bias) }\end{array}$ & Low risk & A - Adequate \\
\hline
\end{tabular}

\section{Miettinen 2000}

Methods Randomisation: sealed envelopes; consecutive adult participants.

Blinding: not described.

Withdrawal/dropout: all participants completed the study.

Follow up: 1-2 months after surgery.

$\begin{array}{ll}\text { Participants } & \text { Inclusion criteria: all consecutive adults admitted for elective colorectal surgery. } \\ & \text { Exclusion criteria: participants who have had bowel preparation for colonoscopy one week before } \\ \text { surgery }(n=5) \text {; participants who were unable to drink PEG-ELS }(n=2) \text {; participants not requiring open- } \\ \text { ing of the bowel }(n=4) \text {; patient who refused to be randomised }(n=1) \text {. }\end{array}$

Disease: colorectal cancer (134); benign tumours (24); inflammatory bowel disease (32); diverticular disease (58); other (19).

Number: 267 (130 male; 137 female).

Age: $16-97$ years.

Location: Kuopio + Oulu, Finland.

Date: 1994-1996.

Antibiotics: ceftriaxone $2 \mathrm{~g}+$ metronidazole $1 \mathrm{~g}$ at the induction of anaesthesia.

Interventions Group A - MBP $(n=138)$ : PEG electrolyte solution, and no solid food on the preoperative day.
Group B - no preparations and normal diet $(n=129)$.

Outcomes $\quad$ Wound infection: Group $A=5$; Group B $=3$.

Anastomotic leakage: Group $A=5$; Group $B=3$ (patients without anastomosis were excluded).

Abdominal abscess: Group A = 3; Group B $=4$.

Non-infectious postoperative complication: Group $A=11$; Group $B=6$.

Reoperation: Group A = 4; Group B = 2: - wound rupture: Group A = 2; Group B = 0;

- perforation of the gallbladder: Group $A=1$; Group $B=0$;

- technical anastomotic failure: Group A = 0; Group $B=1$;

- small bowel occlusions: Group $A=1 ;$ Group $B=2$.

Extra-abdominal infections: Group $A=4$; Group $B=2$.

Postoperative stay (range/days): Group $A=8$; Group $B=8$.

Operation time (range/min): Group A = 120; Group B = 110 . 
Participants with pre-existing disease: Group A $=48$; Group B $=61$.

The differences between the two groups were not significant.

All surgery was carried out by a specialist or a junior surgeon assisted by a specialist.

Excluded participants without anastomosis in the outcome "Anastomotic leakage".

Abdominal abscess: treated conservatively.

No deaths in this trial.

\section{Risk of bias}

\begin{tabular}{lll}
\hline Bias & Authors' judgement & Support for judgement \\
\hline $\begin{array}{l}\text { Allocation concealment } \\
\text { (selection bias) }\end{array}$ & Low risk & A - Adequate \\
\hline
\end{tabular}

\section{Moral 2009}

\begin{tabular}{ll}
\hline Methods & Randomisation: sealed envelops. \\
& Blinding: not described. \\
Withdrawal/Dropout: not described. \\
Follow-up: 30 days after surgery. \\
\hline
\end{tabular}

Participants

Inclusion criteria: elective colorectal surgery with primary anastomosis.

Exclusion criteria: colorectal cancer smaller than $2 \mathrm{~cm}$ not marked by colonoscopy, those who were found to have an abscess of the tumour, diverticulitis, patients who refused to be randomised.

Diseases: benign and malign colorectal diseases.

Number: 139 (50 male; 89 female).

Age: 68 - 70 years.

Location: Barcelona, Spain

Time: May 2005 - Agost 2007.

Antibiotics:

- Oral (single dose 24 hours before the surgery): neomycin + metronidazole;

- Parenteral (single dose at the induction of anaesthesia): ceftriaxone + metronidazole.

Interventions

Group A - MBP ( $n$ = 69): monobasic sodium phosphate + dibasic sodium phosphate or polyethylene glycol

Group B - no MBP $(n=70)$ : 2 cleansing enemas

- the day before the surgery (at 21:00 PM),

- 2 hours before the surgery.

Outcomes

Overall anastomotic leakage: Group A = 5; Group B = 4

- colorectal anastomosis: Group A = 0 (in 31 patients); Group B = 3 (in 19 patients),

- colonic anastomosis: Group A = 5 (in 38 patients); Group B = 1 (in 51 patients).

Mortality: Group A = 2; Group B = 0; 
Moral 2009 (Continued)

Overall wound infection: Group A = 8; Group B $=4$

- colorectal surgery: Group A = 3 (in 31 patients); Group B = 0 (in 19 patients),

- colonic surgery: Group A = 5 (in 38 patients); Group B = 4 (in 51 patients).

$\begin{array}{ll}\text { Notes } & \text { Sample size was calculated. } \\ & \text { Colonic anastomosis: Group A }=38 ; \text { Group B }=51 ; \\ \text { Colorectal anastomosis: Group A }=31 ; \text { Group B }=19 .\end{array}$

Risk of bias

\begin{tabular}{lll}
\hline Bias & Authors' judgement & Support for judgement \\
\hline $\begin{array}{l}\text { Allocation concealment } \\
\text { (selection bias) }\end{array}$ & Low risk & A - Adequate \\
\hline
\end{tabular}

\section{Pena-Soria 2007}

Randomisation: computer-generated numbers.
Blinding: single-blinded (participants were followed by an independent observer).
Withdrawal/dropouts: 2 participants excluded perioperatively; 11 at the moment of surgery (diverting
stoma, tumour perforation, unresectable tumour).
Follow up: 30 days after surgery.
Participants Inclusion criteria: all participants scheduled to undergo an elective colon or proximal rectal resection with primary anastomosis by the same surgeon; without intraoperative colonoscopy; had not had en- doscopic exploration in the prior week; were 18 years of age or older; had given informed consent. Exclusion criteria: immunosuppression; preoperative chemoradiotherapy; diverting stoma; perforated and/or obstructing tumour.
Diseases: colorectal cancer (71\%), inflammatory bowel disease, other.
Number: 97 (49 male; 48 female).
Age: 54 - 82 years.
Location of study: Hospital Clinico San Carlos, Madrid, Spain.
Date: October 2001-July 2005.
Antibiotics: $80 \mathrm{mg}$ of gentamicin $+500 \mathrm{mg}$ of metronidazole 30 minutes before surgery and after $8 \mathrm{~h}$ postoperatively (3 doses).
Interventions $\quad$ Group A - MBP $(n=48): 3$ litres of oral PEG lavage solution plus conventional enemas over $24 \mathrm{~h}$. Group B - no preparation $(n=49)$.
Note: dietary restrictions for both group: $12 \mathrm{~h}$ prior to surgery.

\begin{tabular}{ll} 
Outcomes & Anastomotic failure: Group $A=4$, Group B $=2$. \\
& Wound infection: Group $A=6, G \operatorname{roup} B=6$. \\
& Intra-abdominal sepsis: Group $A=3$, Group B $=0$. \\
& Mortality: Group $A=3$, Group $B=2$. \\
\hline Notes & Sample size was calculated. \\
& No significant differences in demographics were found between the groups. \\
& This trial was presented in abstract form at the 47th Meeting of the Society of Surgery of the Alimentary \\
& Tract.
\end{tabular}

\section{Risk of bias}


Pena-Soria 2007 (Continued)

\begin{tabular}{l}
$\begin{array}{l}\text { Allocation concealment } \\
\text { (selection bias) }\end{array}$ Low risk Adequate \\
\hline
\end{tabular}

Platell 2006

Methods Randomisation: random numbers.

Blinding: single-blind (the treating surgeon was blinded).

Withdrawal/Dropout: 41 exclusion after randomisation

- Group A: 23 resections of the colon and/or rectum without anastomosis;

- Group B: 16 resections, without anastomosis +2 no resections performed.

Follow-up: 6 weeks after surgery.

\section{Participants}

Inclusion criteria: all patients over the age of 18 years undergoing elective resection of the colon and/or rectum with anastomosis and with or without defunctioning stoma.

Exclusion criteria: patients had undergone mechanical bowel preparation within 2 days of operation date, and patients submitted to laparoscopic procedure.

Diseases: colorectal adenoma and cancer, inflammatory bowel disease, diverticular disease, rectal pathology.

Number: 294 (M:F = Group A: 1: 8, Group B: 1:9).

Age: 21 - 93 years.

Location of study: Perth, Western Australia - Australia.

Date: January 2000 - February 2005.

Antibiotics: ticarcillin disodium and clavulanate potassium (3-1 g) with induction of anaesthesia or gentamicin (2 mg/kg) + metronidazole (500 mg).

Interventions

Group A - MBP ( $=147)$ : polyethylene glycol

Group B no MBP ( $n=147)$ : single sodium phosphate enema 2 - 4 hours before surgery.

Outcomes

Anastomotic leaks: Group A = 3; Group B $=7$.

Reoperation: Group A = 0; Group B = 6;

Mortality: Group A = 0; Group B = 1 .

Wound infection: Group A = 19; Group B $=21$.

Intra-abdominal abscess: Group A = 1; Group B $=1$.

Notes The sample size was calculated.

There was a significant difference in severity of the leaks: "the presence of a high volume faecal residue is likely to increase the chance of clinically significant anastomotic leak that will require reoperation".

\section{Risk of bias}

Bias Authors' judgement Support for judgement


Platell 2006 (Continued)
Allocation concealment
Low risk
A - Adequate
(selection bias)

Ram 2005

$\begin{array}{ll}\text { Methods } & \text { Randomisation: participants with even numbers received MBP (Group 1); participants with odd num- } \\ \text { bers did not receive MBP (Group 2). } \\ \text { Blinding: not related. } \\ \text { Withdrawal/dropouts: no details. } \\ \text { Duration of follow up: not reported. }\end{array}$

Inclusion criteria: adult participants admitted for elective colorectal surgery.
Exclusion criteria: antibiotics for the last 10 days before surgery or if there was evidence of infection;
bowel preparation for colonoscopy within 6 days prior to surgery; participants undergoing proctecto-
my with low rectal anastomosis or surgery for polypoid lesion.
Diseases: malignant disease, irritable bowel disease, diverticulosis.
Number: 329 ( 201 male; 128 female).
Age: 57 - 80 years.
Location: Division of General Surgery at the Rabin Medical Center, Tel Aviv, Israel.
Date: 1 April 1999 - 31 March 2002.
Antibiotics: 1 h before induction: 500 mg metronidazole +1 g ceftriaxone; continued for $48 \mathrm{~h}$.

Interventions Group A - MBP $(n=164): 2.4$ g monobasic sodium phosphate +0.9 g dibasic sodium phosphate + lowresidue diet 1 day before surgery.

Group B - low-residue diet 1 day before surgery $(n=165)$.

\begin{tabular}{|c|c|}
\hline Outcomes & 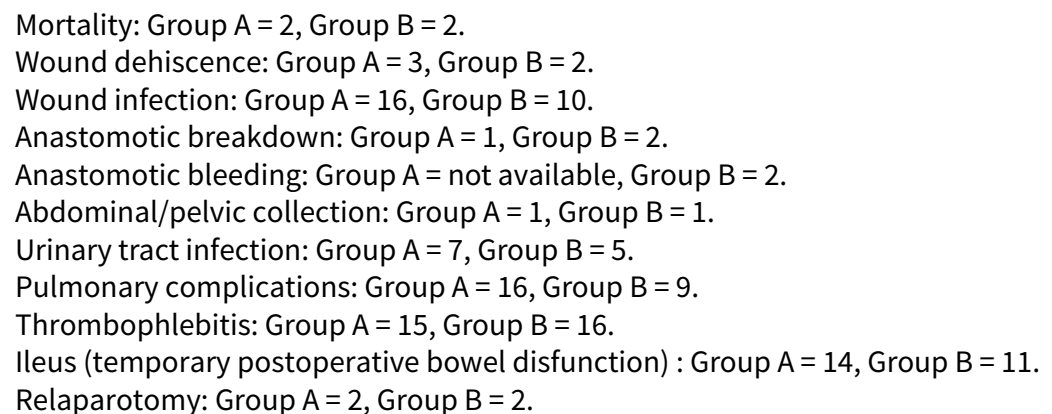 \\
\hline
\end{tabular}

Notes

There were more men than women in both groups, but no statistical difference was found between the two groups (sex, age and diagnosis).

\section{Risk of bias}

\begin{tabular}{lll}
\hline Bias & Authors' judgement & Support for judgement \\
\hline $\begin{array}{l}\text { Allocation concealment } \\
\text { (selection bias) }\end{array}$ & High risk & C-Inadequate \\
\hline
\end{tabular}

Santos 1994

$\begin{array}{ll}\text { Methods } & \text { Randomisation: participants were allocated by a randomised cards. } \\ & \text { Blinding: not described. } \\ & \text { Withdrawal/dropouts: } 5 \% \text { (8/157 cases) were withdrawn, but no dropouts. }\end{array}$


Santos 1994 (Continued)

Follow up: 30 days, or until hospital discharge.

Inclusion criteria: participants admitted for elective colorectal surgery.

Exclusion criteria: participants that had taken antibiotics for at least 15 days before surgery or if there was evidence of infection or any associated disease requiring antibiotic therapy; and participants in whom the MBP was not feasible.

Group A: 5 participants were excluded: associated infectious disease (2), and failure to achieve full MBP (3).

Group B: 3 participants excluded: an intra-abdominal foreign body found during the operation (1), and urinary tract infection (2).

Diseases: 43\% colorectal cancer (68/157); 34\% megacolon (53/157); 6\% inflammatory bowel disease (9/157); $3 \%$ diverticular disease (5/157); $2 \%$ familial adenoma polyposis (3/157); $7 \%$ other (11/157). Number: 157 (72 male; 77 female; 8 undetermined).

Age: $1-93$ years.

Location: Ribeirão Preto, São Paulo - Brazil.

Date: October 1991-December 1992.

Antibiotics: cephalothin $2 \mathrm{~g}+$ metronidazole $1 \mathrm{~g}$ intravenously $2 \mathrm{~h}$ before induction of anaesthesia. Cephalothine $1 \mathrm{~g}$ given at $6 \mathrm{~h}$ and $12 \mathrm{~h}$, and metronidazole $500 \mathrm{mg}$, at $8 \mathrm{~h}$ and $16 \mathrm{~h}$ after the initial dose.

Group A - MBP $(\mathrm{n}=72)$ : laxative or enema:
Laxative: (mineral oil, agar and phenolphthalein) $15 \mathrm{ml}$ taken by mouth 3 times a day for 5 days before
surgery; mannitol (1 litre as a $10 \%$ solution) taken by mouth at the rate of $100 \mathrm{ml}$ per $5 \mathrm{~min}$ at $16: 00 \mathrm{~h}$ on
the day before surgery.
Enema: (water $900 \mathrm{ml}$; glycerin $100 \mathrm{ml}$ ) given once a day for 2 days before surgery.
Children: enema of water and glycerin $(9: 1)$ twice a day for 2 days before surgery.
Group B - low-residue diet and no other MBP $(\mathrm{n}=77)$.

Outcomes

Wound infection: Group A = 17; Group B = 9 .

Anastomotic dehiscence: Group A = 7; Group B $=4$.

Hospital stay: Group A = 2-34 days; Group B = 0-90 days.

Reoperation: Group A = 4; Group B = 1 .

Notes

Representative sample not described.

Participants' associated medical problems: Group A = 53/75; Group B =52/78.

Associated medical disease: Group A $=17$; Group B $=7$.

Most of the participants were operated on by a senior resident (not the consultant).

Included participants without anastomosis.

Reoccurrence was because of leakage.

No death in this trial.

Extra data after stratification had been obtained with personal communication with the author.

\section{Risk of bias}

\begin{tabular}{lll}
\hline Bias & Authors' judgement & Support for judgement \\
\hline $\begin{array}{l}\text { Allocation concealment } \\
\text { (selection bias) }\end{array}$ & Low risk & A - Adequate \\
\hline
\end{tabular}

Scabini 2010

Randomisation: patients were prospectively randomised by individual computer-generated randomi-
sation into two groups.
Blinding: not described.
Withdrawal/dropout: 62 patients were excluded after randomisation due to the exclusion criteria.


Duration of follow-up: 30 days postoperative.

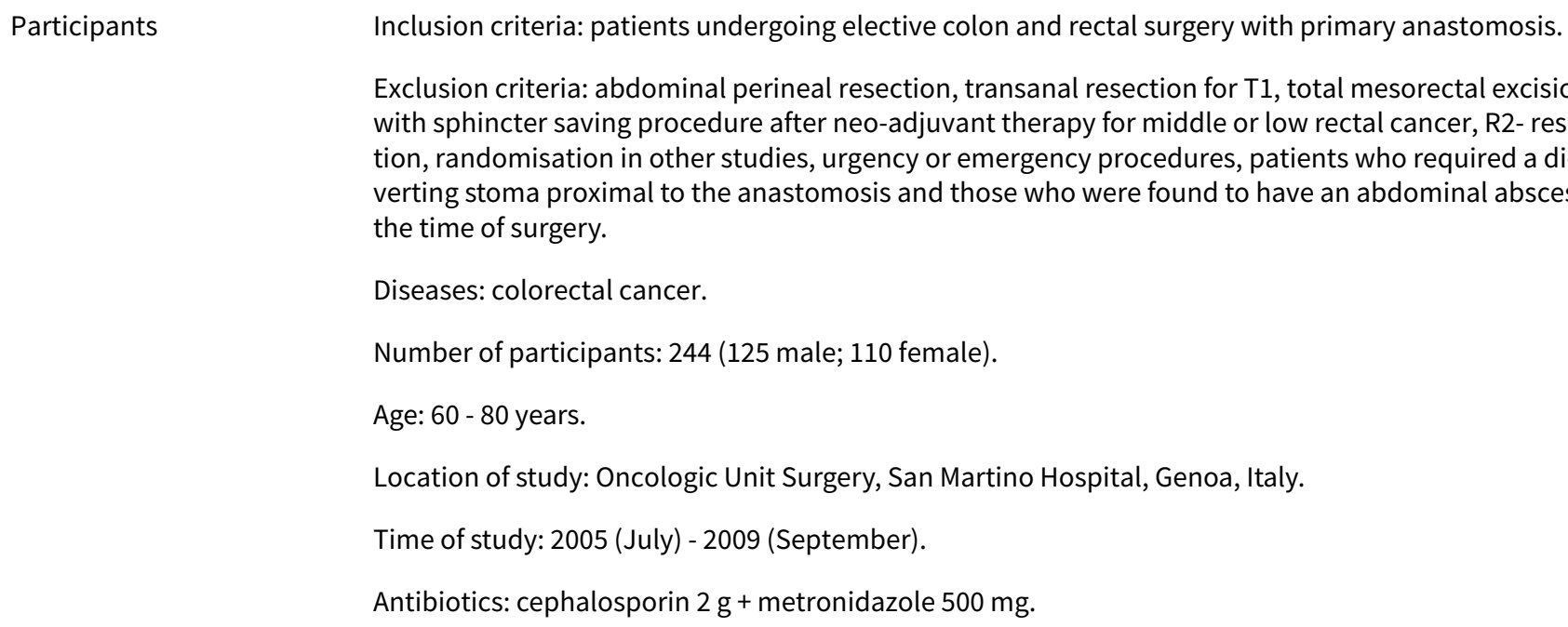
the time of surgery.

Diseases: colorectal cancer.

Number of participants: 244 (125 male; 110 female).

Age: 60 - 80 years.

Location of study: Oncologic Unit Surgery, San Martino Hospital, Genoa, Italy.

Time of study: 2005 (July) - 2009 (September).

Antibiotics: cephalosporin $2 \mathrm{~g}+$ metronidazole $500 \mathrm{mg}$. with sphincter saving procedure after neo-adjuvant therapy for middle or low rectal cancer, R2- resection, randomisation in other studies, urgency or emergency procedures, patients who required a diverting stoma proximal to the anastomosis and those who were found to have an abdominal abscess at

Group B - no MBP $(n=124)$.

Patients undergoing rectal surgery were given one enema one day before surgery.

- Colon: Group A = 2, Group B = 2 .

- Rectum: Group A = 5, Group B = 3.

Wound infection: Group A = 11, Group B = 6 .

Abdominal abscess: Group A = 6, Group B $=3$.

Total of infectious complications: Group A = 24, Group B $=14$.

\begin{tabular}{ll}
\hline Notes & Surgery localization: \\
& - Colon: Group A = 87, Group B = 95. \\
& - Rectum (upper): Group A = 33, Group B = 29. \\
& Surgical procedure: \\
& - Right colectomy: Group A = 40, Group B = 50. \\
& - Transverse colectomy: Group A = 9, Group B = 4. \\
& - Left colectomy: Group A = 13, Group B = 26. \\
& - Sigmoidectomy: Group A = 25, Group B = 15. \\
& - Anterior resection: Group A = 33, Group B = 29.
\end{tabular}

\section{Risk of bias}

\section{Bias}

\section{Authors' judgement Support for judgement}

Low risk A - Adequate 
Tabusso 2002

Methods Randomisation, blinding, withdrawal and dropouts: no details.

Follow up: until hospital discharge (not specified).

Participants Inclusion criteria: participants with colorectal cancer, submitted for elective colorectal surgery.

Exclusion criteria: no details.

Diseases: colorectal cancer.

Number: 47 (21 male, 26 female).

Age: $22-87$ years.

Location of study: Lima, Peru.

Date: October 1999-January 2001.

Antibiotics: intravenously, against anaerobic and Gram-negative bacteria, 30 minutes before surgery.

Interventions Group A - MBP $(n=24)$ : mannitol or PEG electrolyte solution + liquid diet $48 \mathrm{~h}$ before surgery.

Group B - liquid diet $48 \mathrm{~h}$ before surgery $(\mathrm{n}=23)$.

Wound infection: Group $A=2 ;$ Group $B=0$.
Anastomotic leakage: Group $A=5 ;$ Group $B=0$

Anastomotic leakage: Group A = 5; Group B $=0$.

Peritonitis: Group A = 3; Group B = 0 .

Notes Length of hospital stay: Group A = 17-19 days (mean 14); Group B = 6-15 days (mean 11). Analysed only the complications related with the surgery. Participants without anastomosis ( 2 in Group A; 3 in Group B).

\section{Risk of bias}

\begin{tabular}{lll}
\hline Bias & Authors' judgement & Support for judgement \\
\hline $\begin{array}{l}\text { Allocation concealment } \\
\text { (selection bias) }\end{array}$ & Unclear risk & B - Unclear \\
\hline
\end{tabular}

\section{Van't Sant 2010}

Methods It is a subgroup analysis of a prior large multicenter performed by Contant et al.

Randomisation: computer-generated randomisation list; participants were allocated to each intervention by means of numbered sealed envelopes that corresponded to the randomisation list.

Blinding: none.

Withdrawal/dropouts: not described.

Follow-up: first outpatients visit after discharge from the hospital which usually occurred after 2 weeks.

Participants Inclusion criteria: elective low anterior resection with primary anastomosis.

Exclusion criteria: acute laparotomy, laparoscopic colorectal surgery, contraindications for the use of mechanical bowel preparation, an a priori diverting ileostomy, and age less than 18 years old.

Diseases: colorectal cancer, inflammatory bowel disease, other. 
Van't Sant 2010 (Continued)

Participants: 449 (no details about gender).

Age: not described.

Location of study: Netherlands (13 hospitals).

Date: April 1998 - February 2004.

Antibiotics: according to the guideline of each hospital: cefuroxime + metronidazole, cefazolin + metronidazole, cefamandole + metronidazole, gentamycin + metronidazole, amoxicillin + clavulanate, and others.

Interventions Group A - Mechanical bowel preparation $(n=236)$ : PEG + bisacodyl (11 hospitals) or sodium phosphate solution ( 2 hospitals); fluid diet on the day before surgery.

Group B - normal meals $(n=213)$.

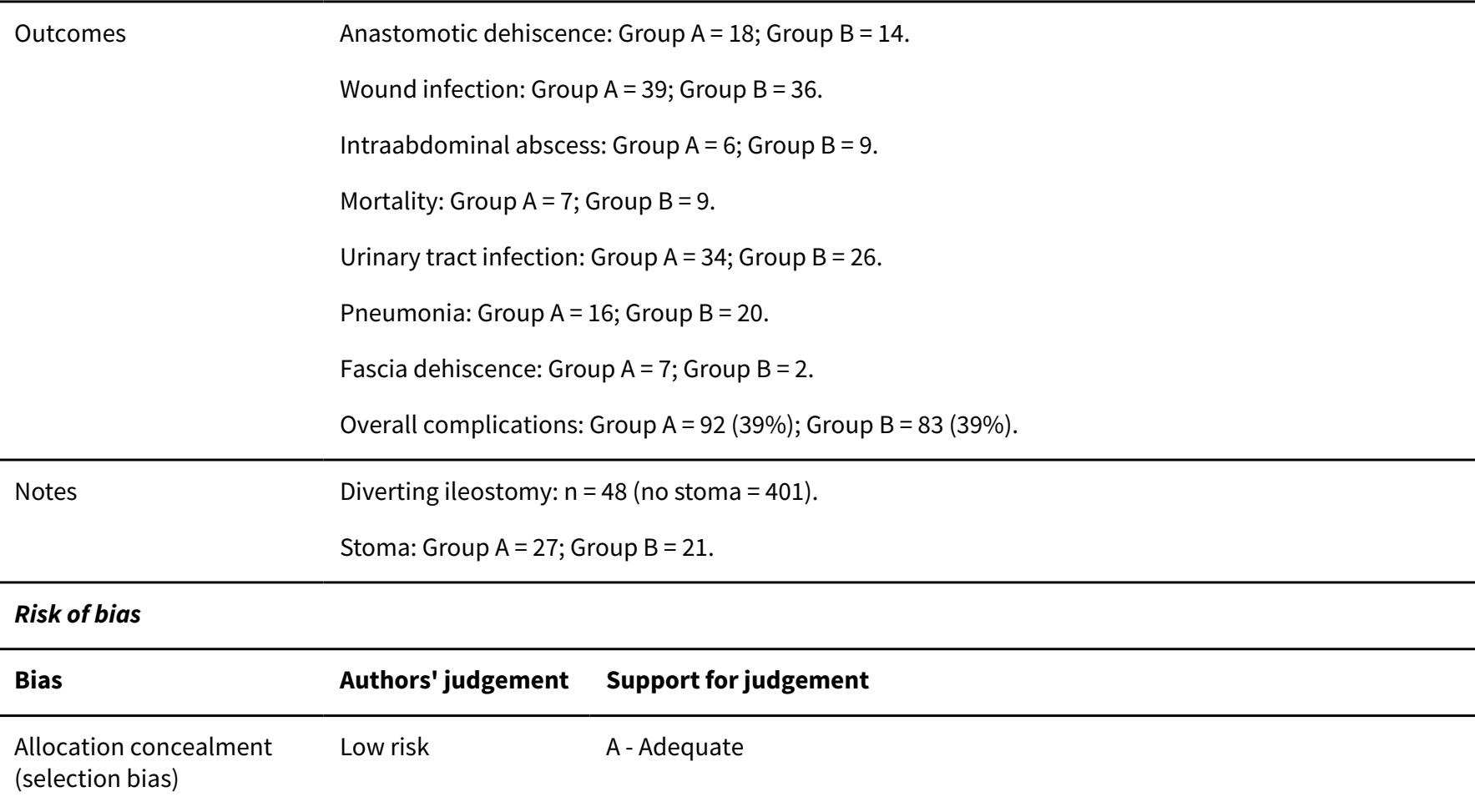

\section{Zmora 2003}

Methods Randomisation: Computer-generated randomisation.

Blinding: not described.

Withdrawal/dropouts: 29 exclusions (18 abdominoperineal resection, 11 proximal stoma)

Follow up: 30 days after surgery.

Participants

Inclusion criteria: participants undergoing elective colon and rectal surgery with primary anastomosis. Exclusion criteria: participants with tumours smaller than $2 \mathrm{~cm}$, who required a diverting stoma proximal to the anastomosis, and those who were found to have an abdominal abscess at the time of surgery.

Diseases: carcinoma of the colon and rectum, diverticular disease, Hartmann's procedure, benign polyp, inflammatory bowel disease, other.

Number: 380 (197 male, 183 female).

Age: 68 yeas (22-92 years).

Location: 2 university-affiliated departments of surgery - Tel Aviv and Haifa, Israel.

Date: July 1997-July 2000 
Zmora 2003 (Continued)

Antibiotics: 3 doses of neomycin + erythromycin + perioperative broad-spectrum IV antibiotics.

\begin{tabular}{|c|c|c|}
\hline Interventions & \multicolumn{2}{|c|}{$\begin{array}{l}\text { Group A - MBP ( } n=187): 1 \text { gallon PEG } 12-16 \text { h before surgery. } \\
\text { Group B - no preparation ( } n=193) \text {. } \\
\text { Note: participants in either group who were planned for rectal surgery were given one phosphate ene- } \\
\text { ma on the day of surgery. }\end{array}$} \\
\hline Outcomes & \multicolumn{2}{|c|}{$\begin{array}{l}\text { Wound infection: Group } A=12, \text { Group } B=11 . \\
\text { Anastomotic leakage: Group } A=7, \text { Group } B=4 . \\
\text { Abdominal abscess: Group } A=2, \text { Group } B=2 . \\
\text { Mortality: Group } A=3 \text {, Group } B=3 \text {. } \\
\text { Overall non surgical complications: Group A }=53 \text {, Group B = 54. }\end{array}$} \\
\hline Notes & \multicolumn{2}{|c|}{ Extra data after stratification had been obtained with personal communication with the author. } \\
\hline \multicolumn{3}{|l|}{ Risk of bias } \\
\hline Bias & Authors' judgement & Support for judgement \\
\hline $\begin{array}{l}\text { Allocation concealment } \\
\text { (selection bias) }\end{array}$ & Low risk & A - Adequate \\
\hline
\end{tabular}

\section{Abbreviations}

ASA = American Society of Anaesthesiologists

$\mathrm{h}=$ hour(s)

$\mathrm{MBP}=$ mechanical bowel preparation

$\mathrm{n}=$ number of participants

PEG = polyethylene glycol

Characteristics of excluded studies [ordered by study ID]

\begin{tabular}{ll}
\hline Study & Reason for exclusion \\
\hline Bretagnol 2007 & $\begin{array}{l}\text { A case-control study; unselected group of participants who underwent elective rectal surgery. In- } \\
\text { cluded laparoscopic surgeries. }\end{array}$ \\
\hline Dorudi 1990 & $\begin{array}{l}\text { Series of consecutive participants. } \\
\text { Treatment for malignant left-sided large bowel obstruction. }\end{array}$ \\
\hline Duthie 1990 & A survey with no control group. \\
\hline Hughes 1972 & $\begin{array}{l}\text { Published data in a conference proceeding. } \\
\text { Most of the data are unclear. } \\
\text { The author did not answer our correspondence, so we could not clarify the details of the trial }\end{array}$ \\
\hline Irving 1987 & No control group. \\
\hline Matheson 1978 & This trial not tested mechanical bowel preparation, but antimicrobials. \\
& The control group received an elemental diet - an especial diet without residues. \\
\hline Memon 1997 & A retrospective, non-randomised study. \\
\hline
\end{tabular}

\section{Characteristics of ongoing studies [ordered by study ID]}


Andreoni, Biffi, Bertani

\begin{tabular}{ll}
\hline Trial name or title & $\begin{array}{l}\text { Effect of Mechanical Bowel Preparation With Polyethylene Glycol Plus Bowel Enema (Glycerine 5\%) } \\
\text { vs Bowel Enema Alone in Patients Candidates to Colorectal Resection for Malignancy. Prospective, } \\
\text { Randomized Clinical Trial }\end{array}$ \\
\hline Methods & Inteventional and randomised \\
\hline Participants & $\begin{array}{l}\text { Patients candidates to colorectal surgery for histologically confirmed colorectal cancer; age 18-80 } \\
\text { years }\end{array}$ \\
\hline Interventions & $\begin{array}{l}\text { Other: mechanical bowel preparation } \\
\text { Other: enema }\end{array}$ \\
\hline Outcomes & $\begin{array}{l}\text { Anastomotic leakage, wound infection, post surgery extra abdominal complications, patient's } \\
\text { symptoms (through questionnaire) }\end{array}$ \\
\hline Starting date & October 2007 \\
\hline Contact information & Emilio Bertani (emilio.bertani@ieo.it) \\
\hline Notes & ClinicalTrials.gov Identifier: NCT00940030 \\
\hline
\end{tabular}

\section{DATA AND ANALYSES}

\section{Comparison 1. Mechanical bowel preparation versus no preparation}

\begin{tabular}{|c|c|c|c|c|}
\hline Outcome or subgroup title & $\begin{array}{l}\text { No. of } \\
\text { studies }\end{array}$ & $\begin{array}{l}\text { No. of } \\
\text { partici- } \\
\text { pants }\end{array}$ & Statistical method & Effect size \\
\hline $\begin{array}{l}1 \text { Anastomosis leakage stratified } \\
\text { for colonic or rectal surgery }\end{array}$ & 11 & & Peto Odds Ratio (Peto, Fixed, 95\% Cl) & Subtotals only \\
\hline $\begin{array}{l}\text { 1.1 Leakage after low anterior re- } \\
\text { section }\end{array}$ & 7 & 846 & Peto Odds Ratio (Peto, Fixed, 95\% Cl) & $0.88[0.55,1.40]$ \\
\hline 1.2 Leakage after colonic surgery & 8 & 3147 & Peto Odds Ratio (Peto, Fixed, 95\% Cl) & $0.85[0.58,1.26]$ \\
\hline $\begin{array}{l}2 \text { Overall anastomotic leakage for } \\
\text { colorectal surgery }\end{array}$ & 13 & 4533 & Peto Odds Ratio (Peto, Fixed, $95 \% \mathrm{Cl}$ ) & $0.99[0.74,1.31]$ \\
\hline 3 Mortality & 11 & 4166 & Peto Odds Ratio (Peto, Fixed, 95\% Cl) & $0.93[0.58,1.47]$ \\
\hline 4 Peritonitis & 10 & 3983 & Peto Odds Ratio (Peto, Fixed, $95 \% \mathrm{Cl}$ ) & $0.74[0.50,1.08]$ \\
\hline 5 Reoperation & 11 & 4319 & Peto Odds Ratio (Peto, Fixed, 95\% Cl) & $1.04[0.81,1.34]$ \\
\hline 6 Wound infection & 13 & 4595 & Peto Odds Ratio (Peto, Fixed, $95 \% \mathrm{Cl}$ ) & $1.16[0.95,1.42]$ \\
\hline $\begin{array}{l}7 \text { Infectious extra-abdominal } \\
\text { complications }\end{array}$ & 6 & 3575 & Peto Odds Ratio (Peto, Fixed, 95\% Cl) & $1.05[0.85,1.30]$ \\
\hline
\end{tabular}




\begin{tabular}{|c|c|c|c|c|}
\hline Outcome or subgroup title & $\begin{array}{l}\text { No. of } \\
\text { studies }\end{array}$ & $\begin{array}{l}\text { No. of } \\
\text { partici- } \\
\text { pants }\end{array}$ & Statistical method & Effect size \\
\hline $\begin{array}{l}8 \text { Non-infectious extra-abdominal } \\
\text { complications }\end{array}$ & 6 & 2346 & Peto Odds Ratio (Peto, Fixed, 95\% Cl) & $0.98[0.71,1.36]$ \\
\hline $\begin{array}{l}9 \text { Sensitivity analysis } 1 \text { - Including } \\
\text { only studies with adequate ran- } \\
\text { domisation }\end{array}$ & 9 & & Odds Ratio (M-H, Random, 95\% Cl) & Subtotals only \\
\hline $\begin{array}{l}9.1 \text { Overall anastomotic leakage } \\
\text { for colorectal surgery }\end{array}$ & 9 & 3854 & Odds Ratio (M-H, Random, 95\% Cl) & $0.88[0.64,1.23]$ \\
\hline 9.2 Wound infection & 9 & 3875 & Odds Ratio (M-H, Random, 95\% Cl) & $1.13[0.91,1.40]$ \\
\hline $\begin{array}{l}10 \text { Sensitivity analysis } 2 \text { - Stud- } \\
\text { ies including only patients with } \\
\text { anastomosis }\end{array}$ & 8 & & Odds Ratio (M-H, Random, 95\% Cl) & Subtotals only \\
\hline $\begin{array}{l}10.1 \text { Overall anastomotic leakage } \\
\text { for colorectal surgery }\end{array}$ & 8 & 3792 & Odds Ratio (M-H, Random, 95\% Cl) & $0.92[0.60,1.41]$ \\
\hline 10.2 Wound infection & 8 & 3837 & Odds Ratio (M-H, Random, 95\% Cl) & $1.07[0.86,1.35]$ \\
\hline
\end{tabular}

Analysis 1.1. Comparison 1 Mechanical bowel preparation versus no preparation,
Outcome 1 Anastomosis leakage stratified for colonic or rectal surgery.

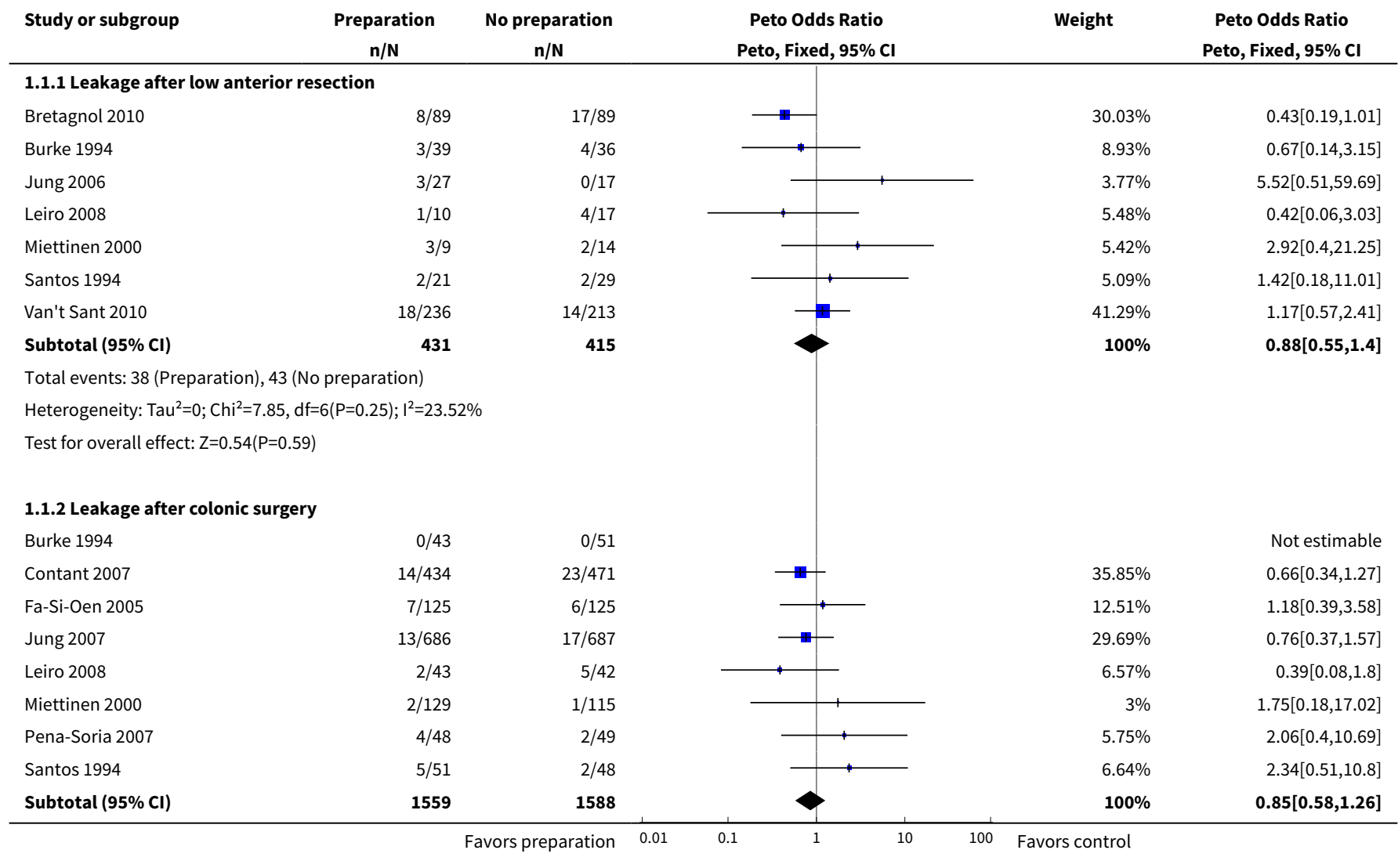




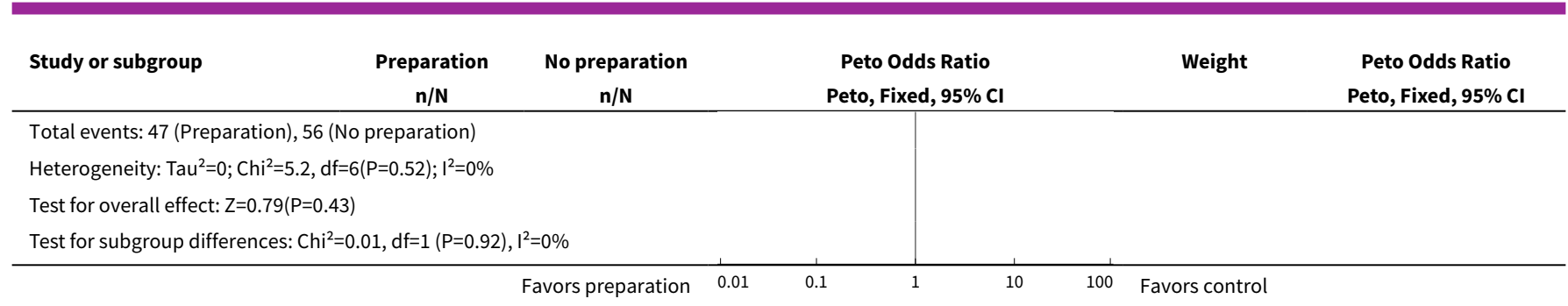

Analysis 1.2. Comparison 1 Mechanical bowel preparation versus no preparation, Outcome 2 Overall anastomotic leakage for colorectal surgery.

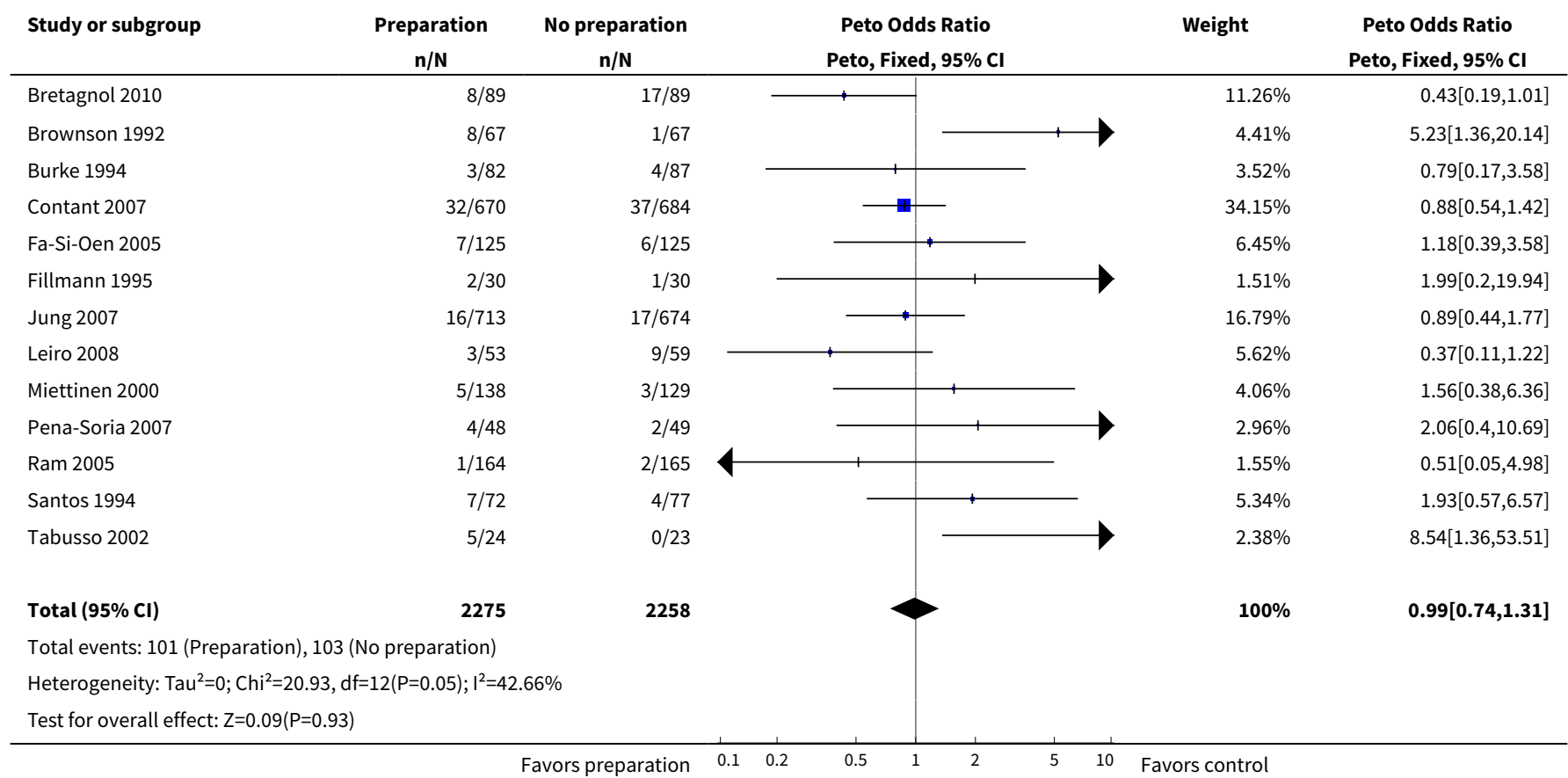

\section{Analysis 1.3. Comparison 1 Mechanical bowel preparation versus no preparation, Outcome 3 Mortality.}

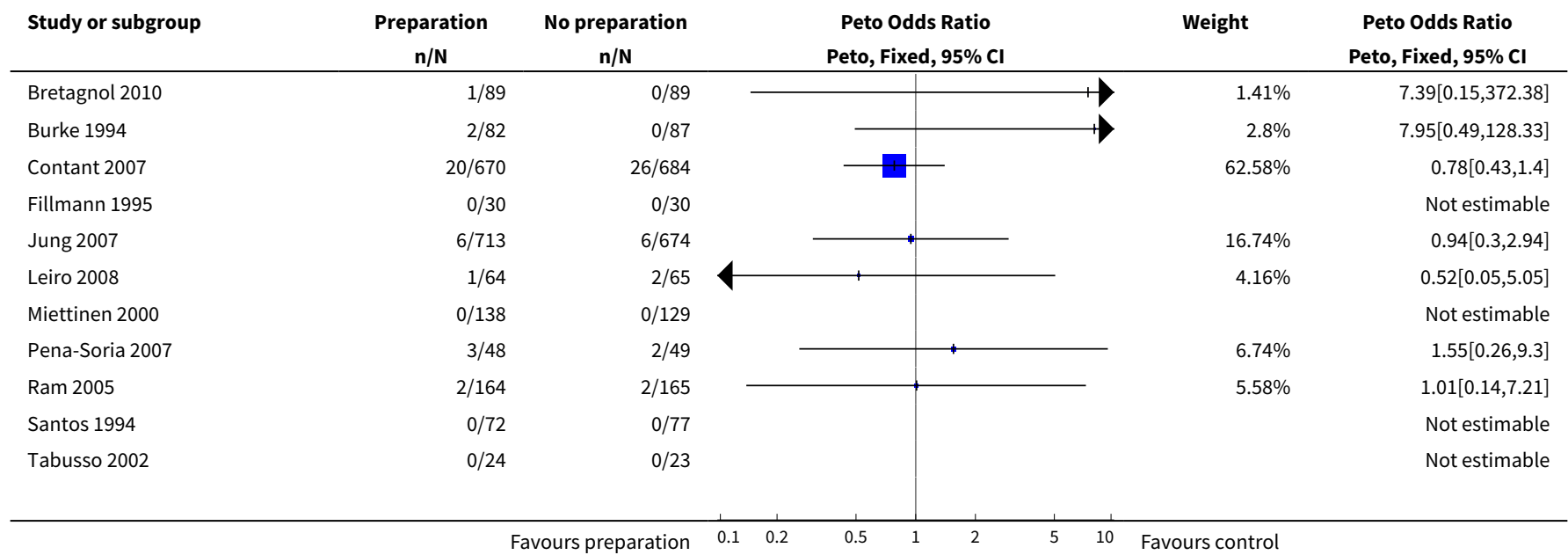




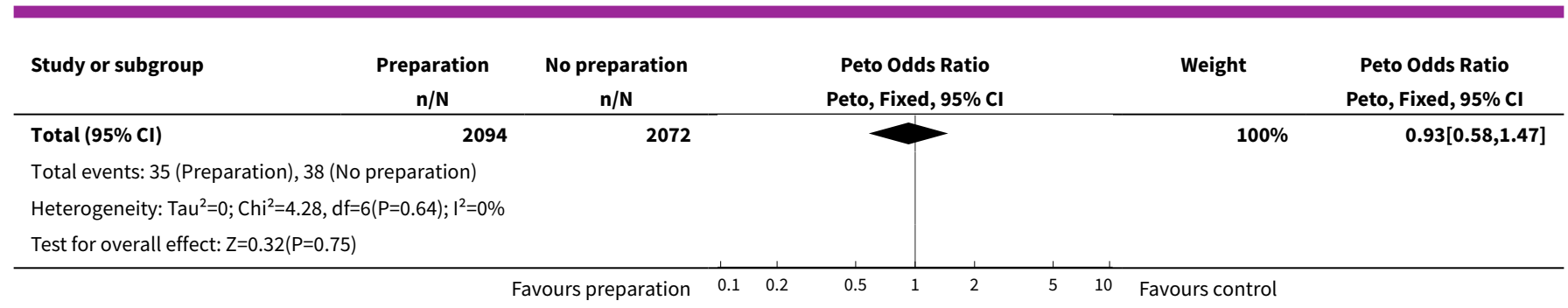

\section{Analysis 1.4. Comparison 1 Mechanical bowel preparation versus no preparation, Outcome 4 Peritonitis.}

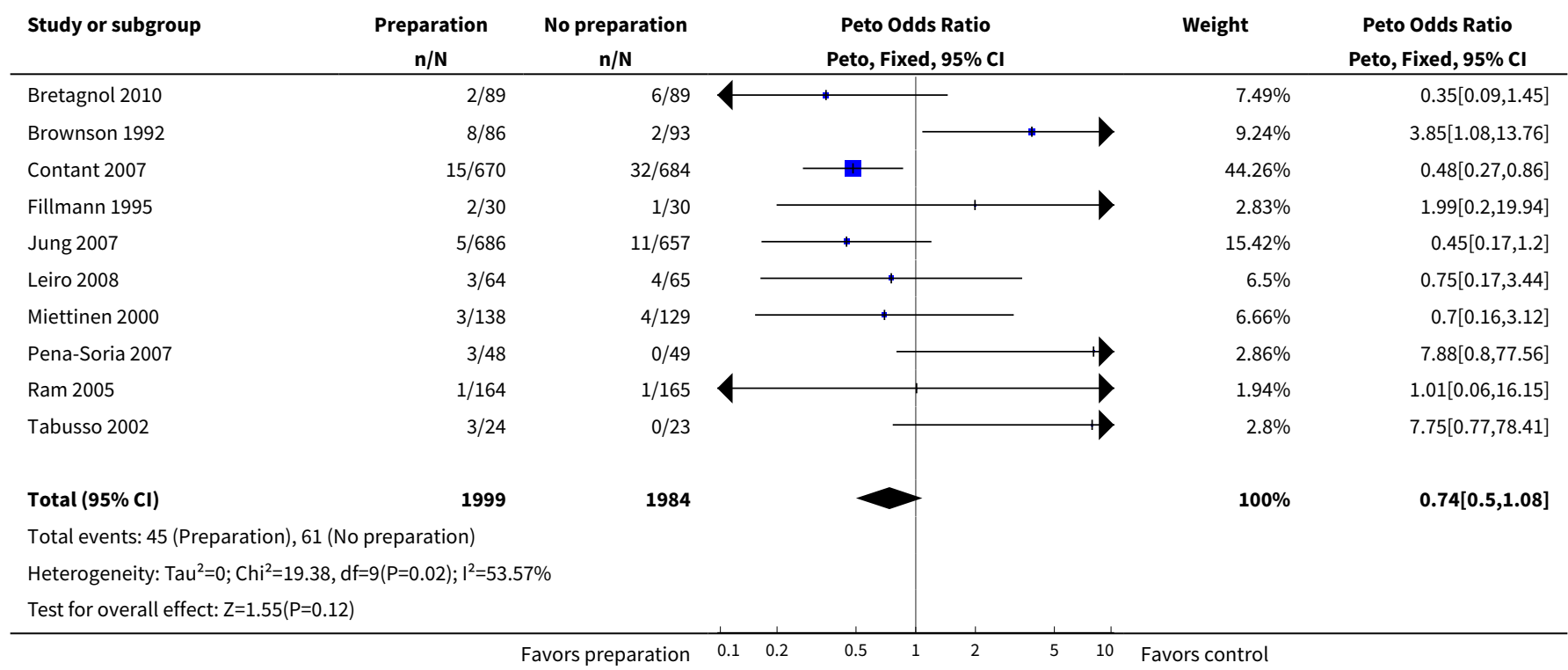

\section{Analysis 1.5. Comparison 1 Mechanical bowel preparation versus no preparation, Outcome 5 Reoperation.}

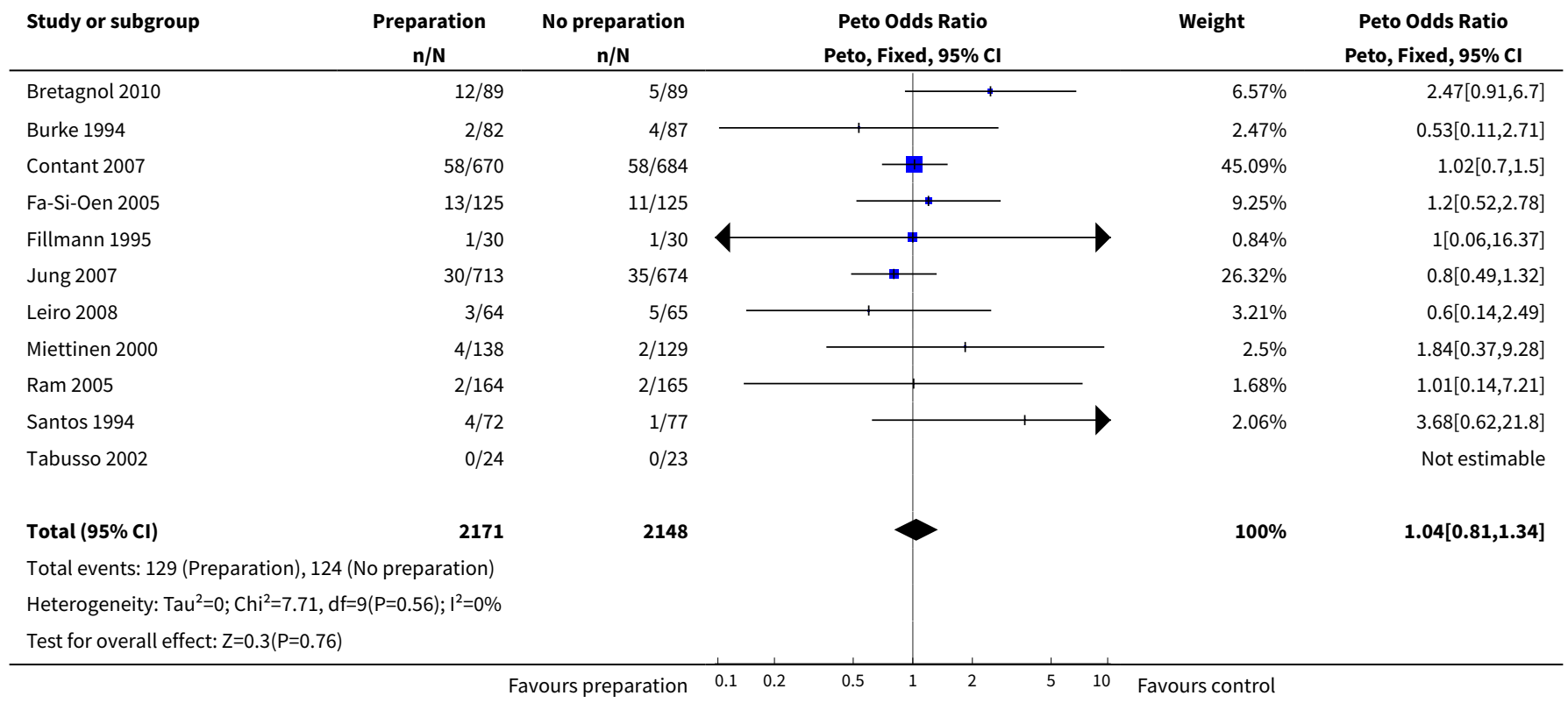


Analysis 1.6. Comparison 1 Mechanical bowel preparation versus no preparation, Outcome 6 Wound infection.

\begin{tabular}{|c|c|c|c|c|c|}
\hline Study or subgroup & $\begin{array}{c}\text { Preparation } \\
n / N\end{array}$ & $\begin{array}{c}\text { No preparation } \\
n / N\end{array}$ & $\begin{array}{l}\text { Peto Odds Ratio } \\
\text { Peto, Fixed, } 95 \% \mathrm{Cl}\end{array}$ & Weight & $\begin{array}{l}\text { Peto Odds Ratio } \\
\text { Peto, Fixed, } 95 \% \mathrm{Cl}\end{array}$ \\
\hline Bretagnol 2010 & $3 / 89$ & $1 / 89$ & & $1.05 \%$ & $2.77[0.38,19.97]$ \\
\hline Brownson 1992 & $5 / 86$ & $7 / 93$ & 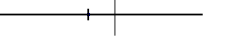 & $3.01 \%$ & $0.76[0.24,2.45]$ \\
\hline Burke 1994 & $4 / 82$ & $3 / 87$ & 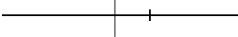 & $1.81 \%$ & $1.43[0.32,6.47]$ \\
\hline Contant 2007 & $90 / 670$ & $96 / 684$ & - & $42.97 \%$ & $0.95[0.7,1.3]$ \\
\hline Fa-Si-Oen 2005 & 9/125 & $7 / 125$ & & $4.02 \%$ & $1.3[0.47,3.59]$ \\
\hline Fillmann 1995 & $1 / 30$ & $2 / 30$ & & $0.78 \%$ & $0.5[0.05,5.02]$ \\
\hline Jung 2007 & $55 / 713$ & $42 / 674$ & $\div$ & $24.15 \%$ & $1.26[0.83,1.9]$ \\
\hline Leiro 2008 & $10 / 64$ & $10 / 65$ & & $4.56 \%$ & $1.02[0.39,2.63]$ \\
\hline Miettinen 2000 & $5 / 138$ & $3 / 129$ & & $2.08 \%$ & $1.56[0.38,6.36]$ \\
\hline Pena-Soria 2007 & $6 / 48$ & $6 / 49$ & & $2.84 \%$ & $1.02[0.31,3.41]$ \\
\hline Ram 2005 & $16 / 164$ & $10 / 165$ & $\rightarrow$ & $6.43 \%$ & $1.66[0.75,3.69]$ \\
\hline Santos 1994 & $17 / 72$ & $9 / 77$ & & $5.78 \%$ & $2.28[0.98,5.29]$ \\
\hline Tabusso 2002 & $2 / 24$ & $0 / 23$ & & $0.52 \%$ & $7.4[0.45,122.11]$ \\
\hline Total $(95 \% \mathrm{Cl})$ & 2305 & 2290 & > & $100 \%$ & $1.16[0.95,1.42]$ \\
\hline \multicolumn{6}{|c|}{ Total events: 223 (Preparation), 196 (No preparation) } \\
\hline \multicolumn{6}{|c|}{ Heterogeneity: $\operatorname{Tau}^{2}=0 ; \mathrm{Chi}^{2}=8.79, \mathrm{df}=12(\mathrm{P}=0.72) ; \mathrm{I}^{2}=0 \%$} \\
\hline \multicolumn{6}{|c|}{ Test for overall effect: $Z=1.44(P=0.15)$} \\
\hline
\end{tabular}

\section{Analysis 1.7. Comparison 1 Mechanical bowel preparation versus no preparation, Outcome 7 Infectious extra-abdominal complications.}

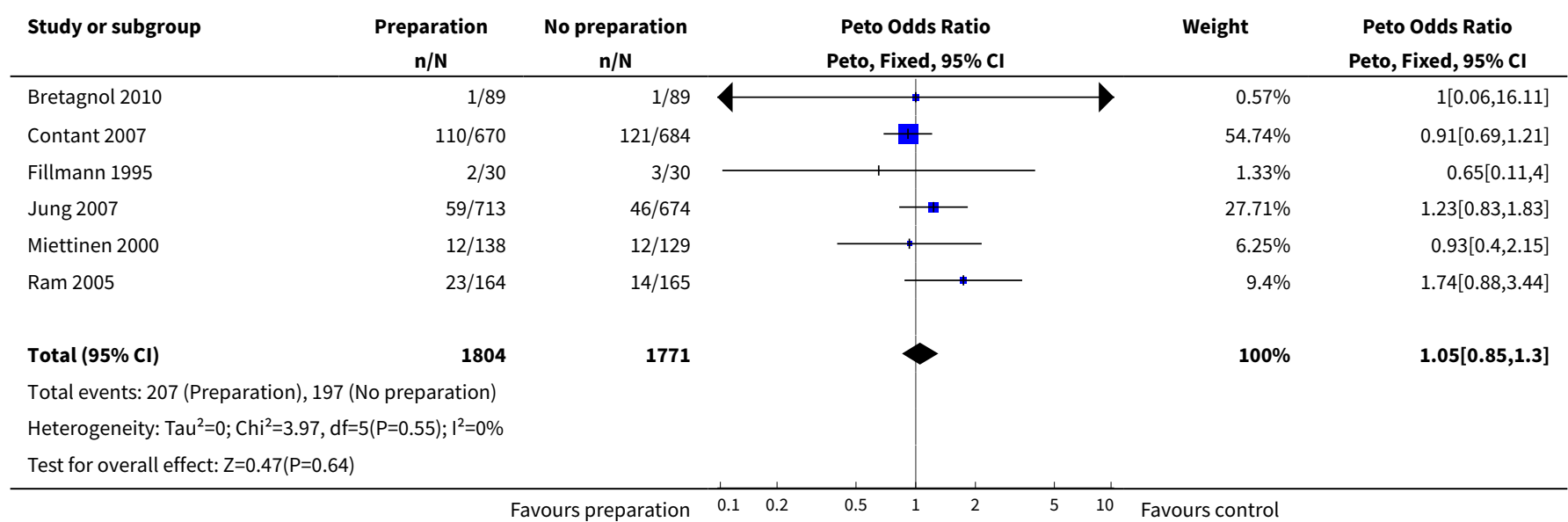


Analysis 1.8. Comparison 1 Mechanical bowel preparation versus no preparation, Outcome 8 Non-infectious extra-abdominal complications.

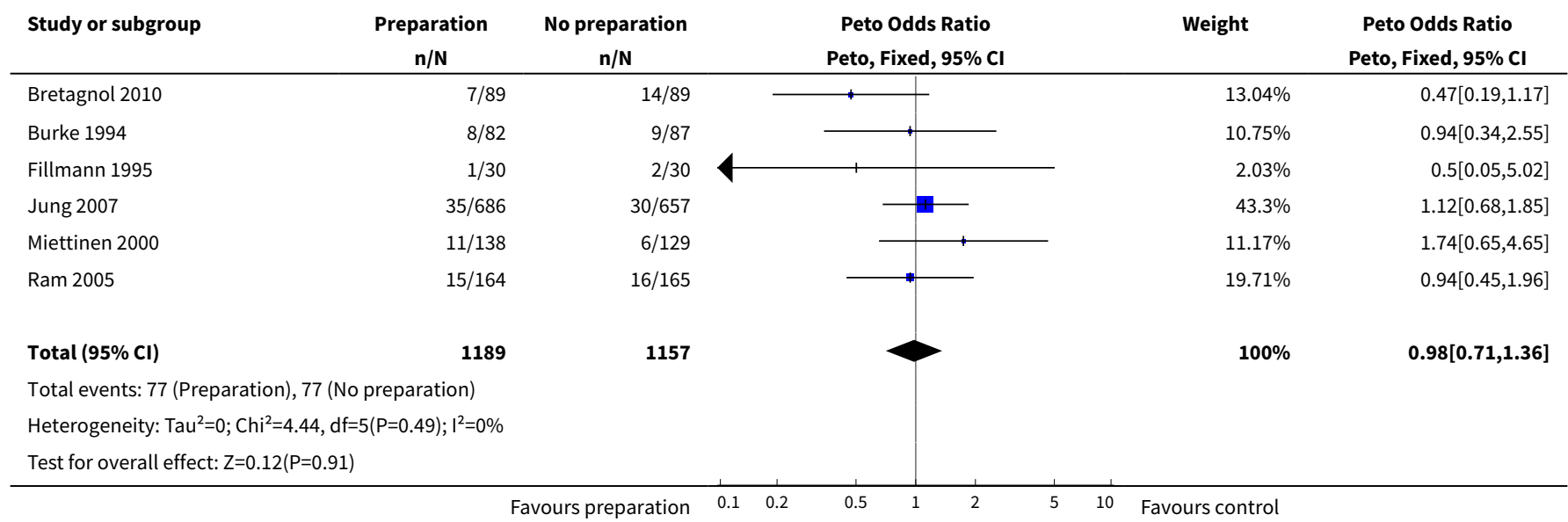

Analysis 1.9. Comparison 1 Mechanical bowel preparation versus no preparation, Outcome 9 Sensitivity analysis 1 - Including only studies with adequate randomisation.

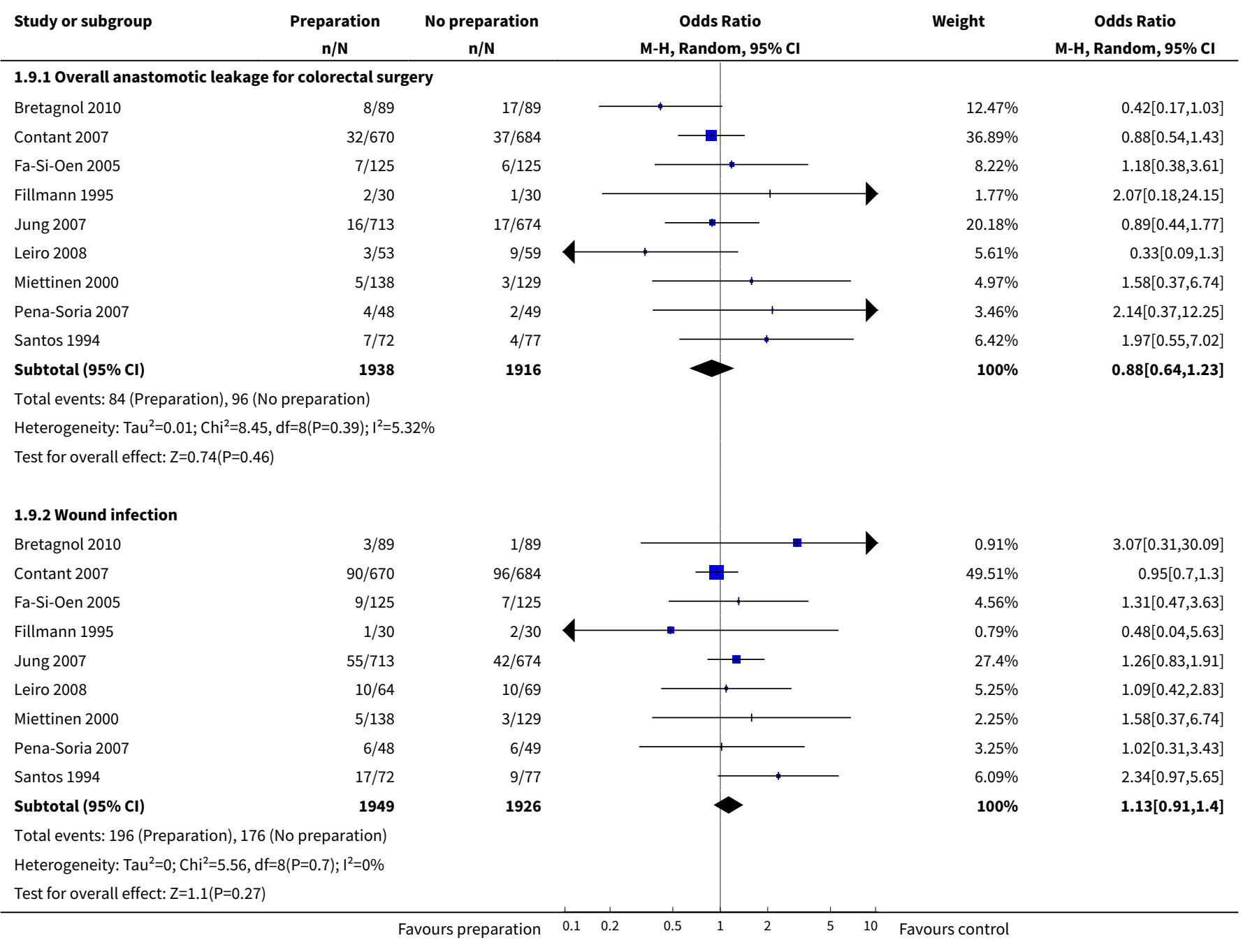


Analysis 1.10. Comparison 1 Mechanical bowel preparation versus no preparation, Outcome 10 Sensitivity analysis 2 - Studies including only patients with anastomosis.

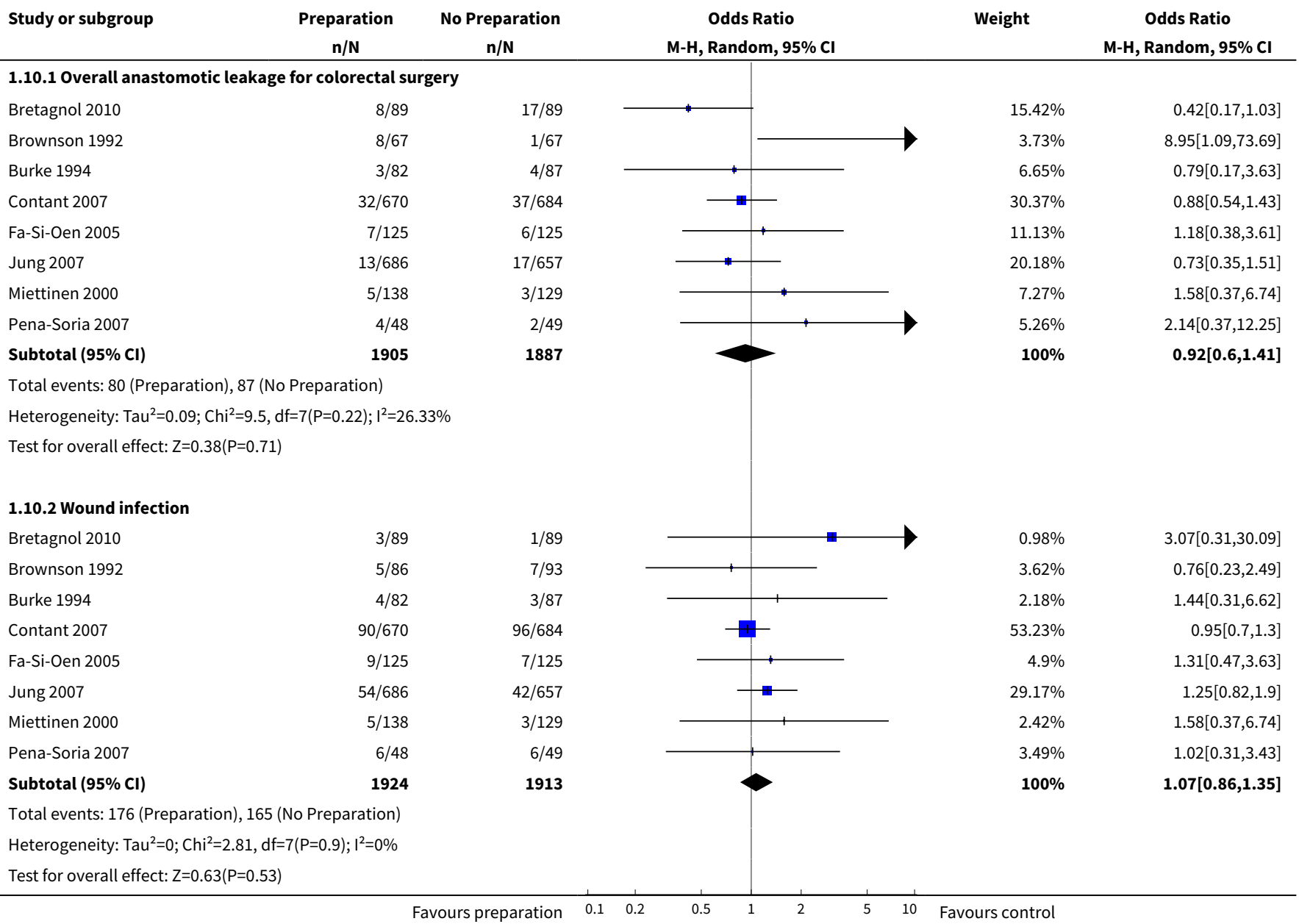

\section{Comparison 2. Mechanical bowel preparation versus rectal enema}

\begin{tabular}{lllll}
\hline Outcome or subgroup title & $\begin{array}{l}\text { No. of } \\
\text { studies }\end{array}$ & $\begin{array}{l}\text { No. of } \\
\text { partici- } \\
\text { pants }\end{array}$ & Statistical method & Effect size \\
\hline $\begin{array}{l}\text { 1 Anastomotic leakage for colorectal } \\
\text { surgery }\end{array}$ & 3 & 763 & Odds Ratio (M-H, Fixed, 95\% Cl) & $1.43[0.71,2.87]$ \\
\hline $\begin{array}{l}1.1 \text { Leakage after rectal surgery } \\
1.2 \text { Leakage after colonic surgery }\end{array}$ & 3 & 195 & Odds Ratio (M-H, Fixed, 95\% Cl) & $0.93[0.34,2.52]$ \\
\hline 2 Overall anastomotic leakage & 5 & 568 & Odds Ratio (M-H, Fixed, 95\% Cl) & $2.15[0.79,5.84]$ \\
\hline 3 Mortality & 1210 & Odds Ratio (M-H, Fixed, 95\% Cl) & $1.32[0.74,2.36]$ \\
\hline 4 Peritonitis / Abscess & 5 & 1210 & Odds Ratio (M-H, Fixed, 95\% Cl) & $1.47[0.56,3.90]$ \\
\hline \hline
\end{tabular}




\begin{tabular}{lllll}
\hline Outcome or subgroup title & $\begin{array}{l}\text { No. of } \\
\text { studies }\end{array}$ & $\begin{array}{l}\text { No. of } \\
\text { partici- } \\
\text { pants }\end{array}$ & Statistical method & Effect size \\
\hline 5 Reoperation & 2 & 447 & Odds Ratio (M-H, Fixed, 95\% Cl) & $0.86[0.32,2.33]$ \\
\hline 6 Wound infection & 5 & 1210 & Odds Ratio (M-H, Fixed, 95\% Cl) & $1.26[0.85,1.88]$ \\
\hline
\end{tabular}

Analysis 2.1. Comparison 2 Mechanical bowel preparation versus rectal enema, Outcome 1 Anastomotic leakage for colorectal surgery.

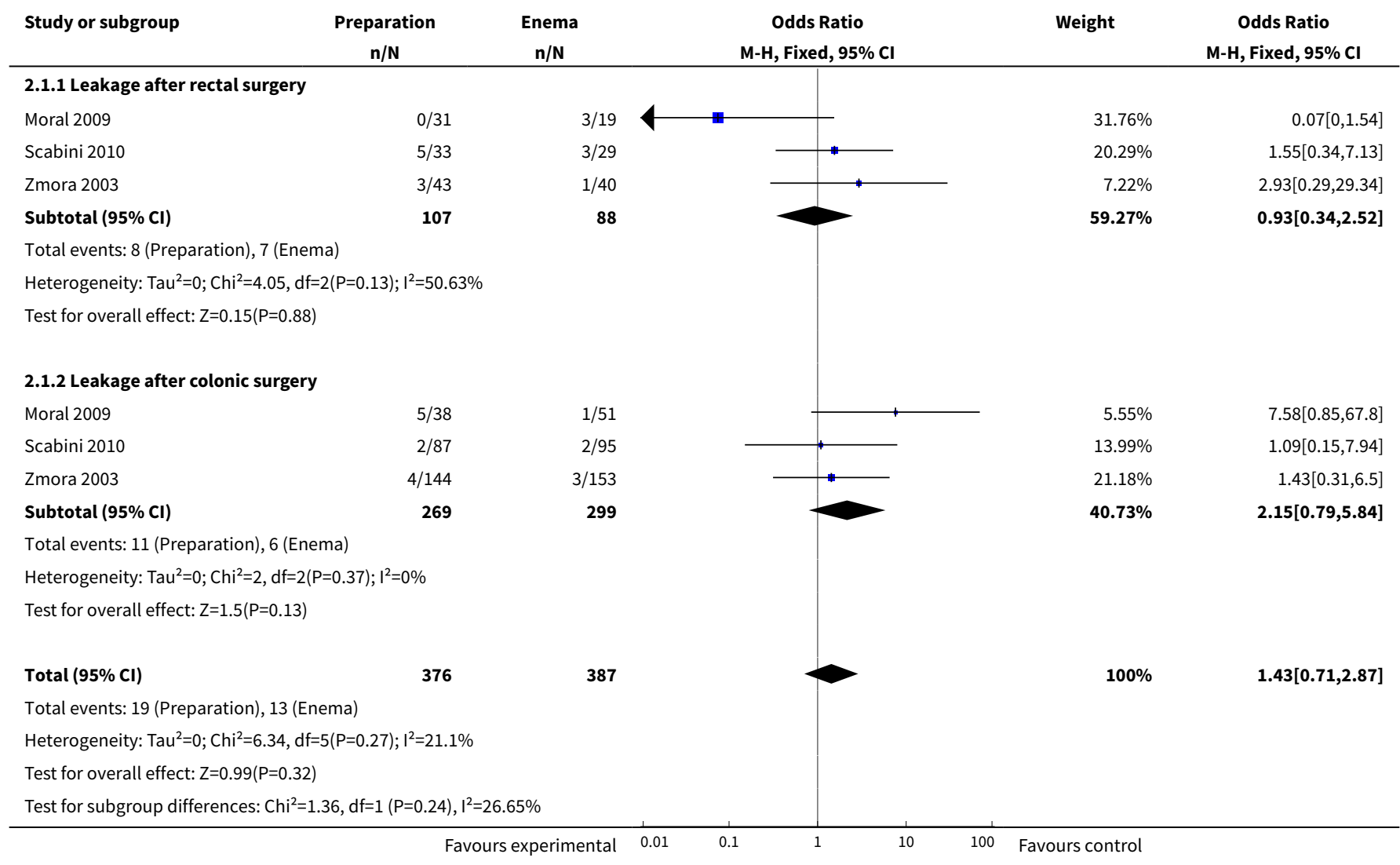

Analysis 2.2. Comparison 2 Mechanical bowel preparation versus rectal enema, Outcome 2 Overall anastomotic leakage.

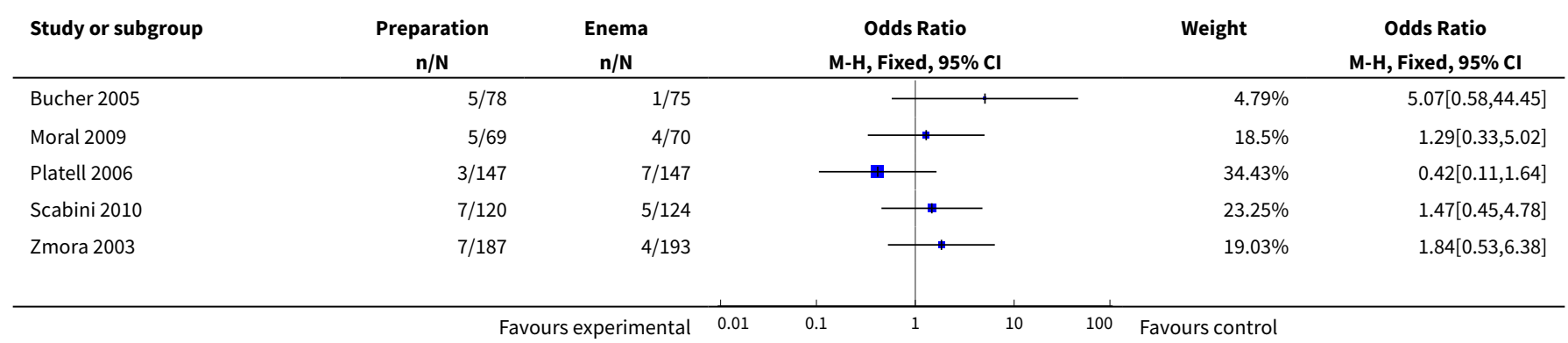




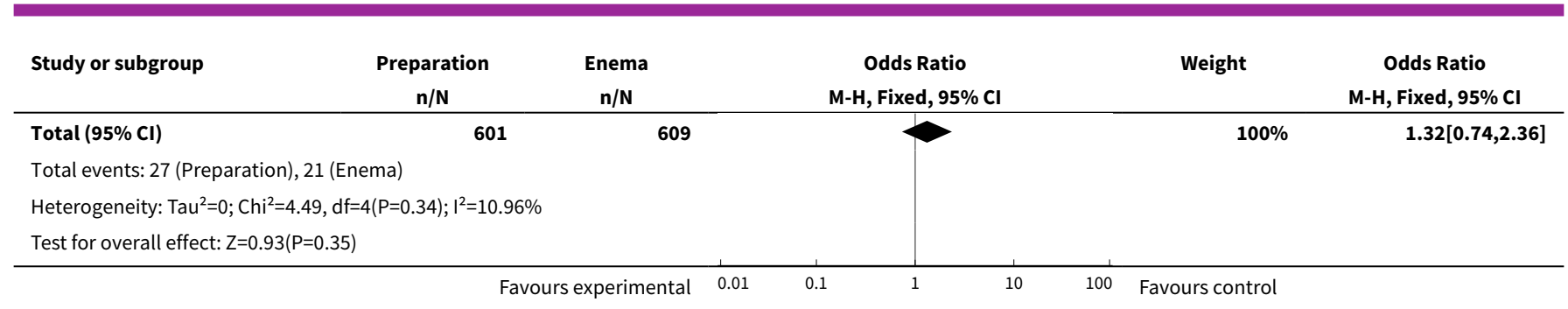

Analysis 2.3. Comparison 2 Mechanical bowel preparation versus rectal enema, Outcome 3 Mortality.

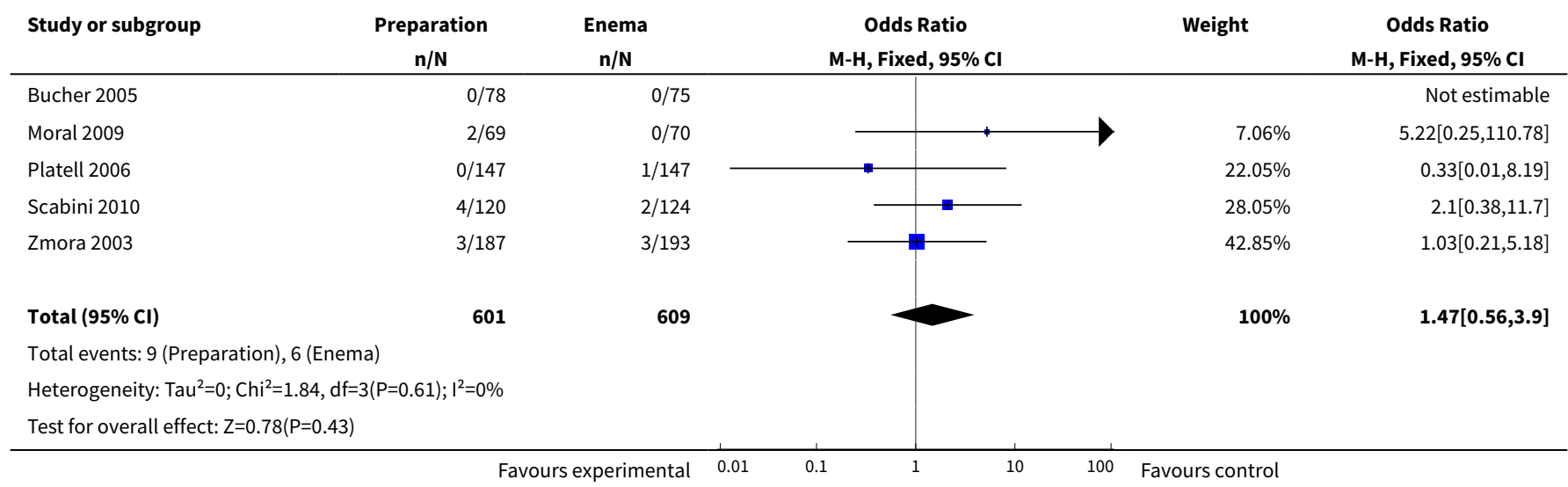

Analysis 2.4. Comparison 2 Mechanical bowel preparation versus rectal enema, Outcome 4 Peritonitis / Abscess.

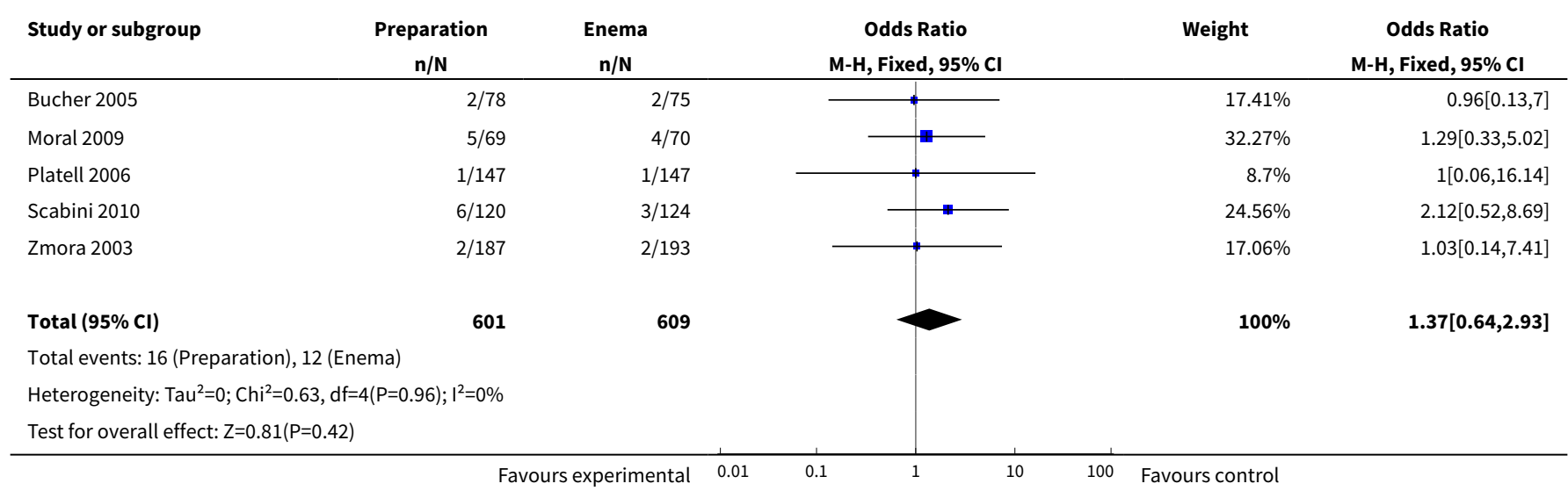

Analysis 2.5. Comparison 2 Mechanical bowel preparation versus rectal enema, Outcome 5 Reoperation.

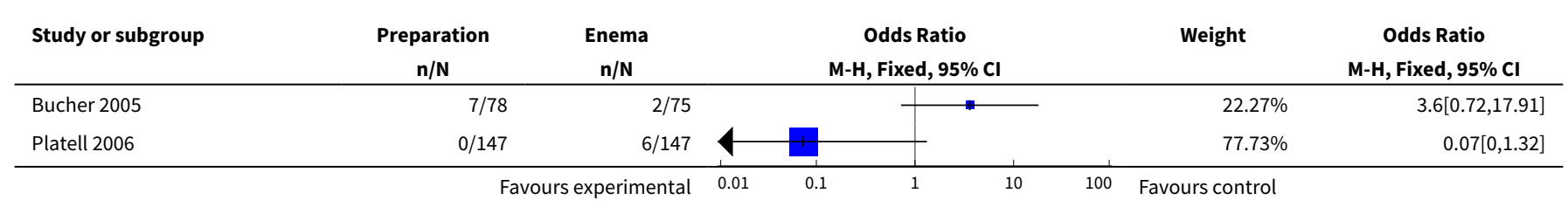




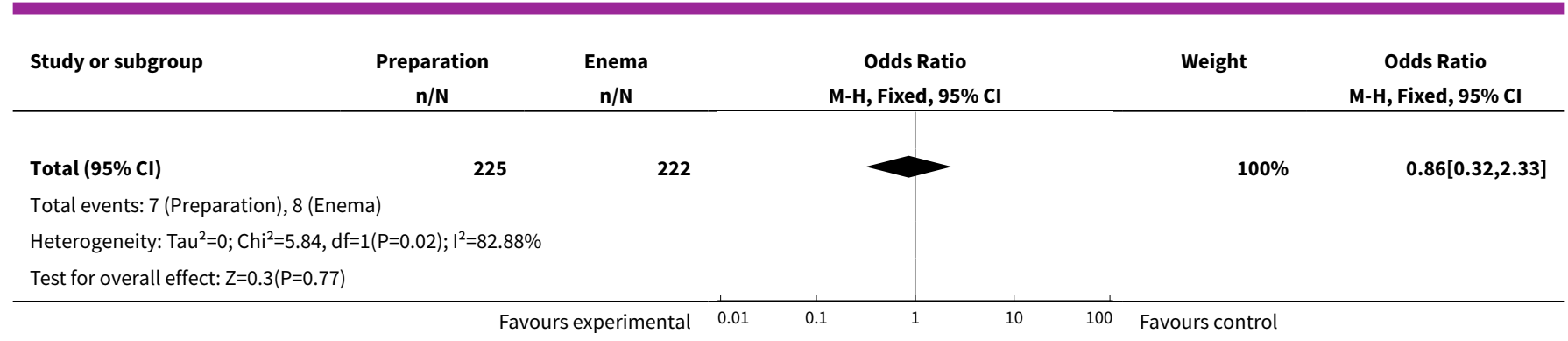

Analysis 2.6. Comparison 2 Mechanical bowel preparation versus rectal enema, Outcome 6 Wound infection.

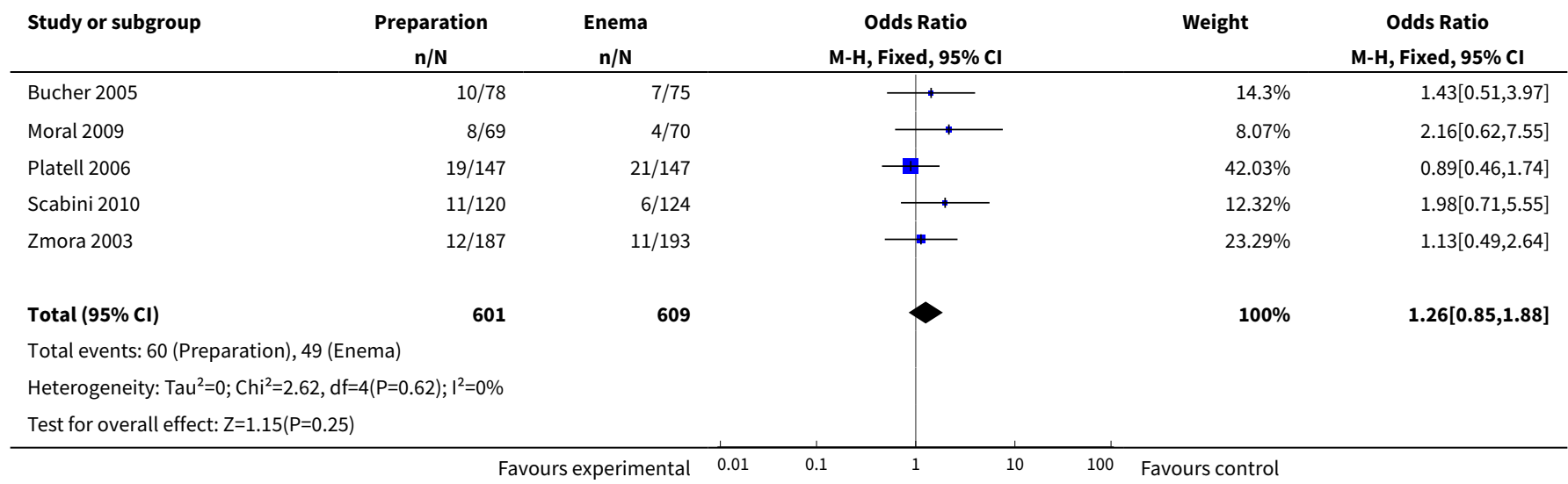

\section{WHAT'S NEW}

\begin{tabular}{lll}
\hline Date & Event & Description \\
\hline 22 July 2011 & $\begin{array}{l}\text { New citation required but conclusions } \\
\text { have not changed }\end{array}$ & $\begin{array}{l}\text { At this update six trials and a new comparison (Mechanical bow- } \\
\text { el preparation versus enema) were added. Altogether eighteen } \\
\text { trials were analysed. The conclusions are not changed }\end{array}$ \\
\hline 22 July 2011 & New search has been performed & See above \\
\hline
\end{tabular}

\section{HISTORY}

Protocol first published: Issue 4, 1999

Review first published: Issue 2, 2003

\begin{tabular}{lll}
\hline Date & Event & Description \\
\hline 3 October 2008 & $\begin{array}{l}\text { New citation required but conclusions } \\
\text { have not changed }\end{array}$ & $\begin{array}{l}\text { Three more studies have been identified and included. One study } \\
\text { previously published as abstract now exists in full article version. } \\
\text { More sensitivity analysis have been performed. The overall con- } \\
\text { clusions have not been changed. }\end{array}$ \\
& $\begin{array}{l}\text { Two abstracts included at the first update were published as full } \\
\text { articles: dates were completed. Four trials were included. The re- }\end{array}$
\end{tabular}




\begin{tabular}{lll}
\hline Date & Event & Description \\
\hline 5 September 2008 & New search has been performed & $\begin{array}{l}\text { sults had a small modification, but the conclusion remains un- } \\
\text { changed. }\end{array}$ \\
\hline 13 March 2008 & $\begin{array}{l}\text { New citation required and conclusions } \\
\text { have changed }\end{array}$ & Substantive amendment \\
\hline
\end{tabular}

\section{CONTRIBUTIONS OFAUTHORS}

Conceiving the review: DM, ANA.

Designing the review: KFG, DM, AAC, ANA.

Co-ordinating the review: KFG.

Developing search strategy: AAC.

Undertaking searches: KFG, AAC.

Screening search results: $K F G$, DM, AAC.

Organising retrieval of papers: KFG, DM, AAC.

Screening retrieved papers against inclusion criteria: KFG, DM, AAC.

Appraising quality of papers: KFG, DM, AAC.

Abstracting data from papers: KFG, DM, AAC.

Writing to authors of papers for additional information: DM, KFG.

Providing additional data about papers: DM, KFG.

Obtaining and screening data on unpublished studies: Not applicable.

Data management for the review: KFG, DM, AAC, PWJ.

Entering data into RevMan: KFG, PWJ.

Analysis of data: KFG, DM, AAC, PWJ

Interpretation of data: KFG, DM, AAC, PWJ.

Providing a methodological perspective: KFG, DM, AAC, ANA.

Providing a clinical perspective: KFG, DM, AAC, PWJ.

Providing a policy perspective: DM.

Providing a consumer perspective: none.

Writing the review: KFG, DM, AAC, PWJ.

Providing general advice on the review: DM , ANA.

Securing funding for the review: DM, ANA, PWJ.

Performing previous work that was the foundation of current study: Not applicable.

\section{DECLARATIONS OF INTEREST}

There are no conflicts of interest relating to this review.

\section{SOURCES OF SUPPORT}

\section{Internal sources}

- Clinical Trials and Meta-analyses Unit, Federal University of São Paulo, Brazil.

- Surgical Gastroenterology Department, Federal University of São Paulo, Brazil.

- Cochrane Colorectal Cancer Group, Denmark.

\section{External sources}

- The Valerie Jefferson Fund, UK.

- SanMed - Materiais Médicos Hospitalares Ltda., Brazil.

\section{NOTES}

None. 


\section{N D EX TERMS}

\section{Medical Subject Headings (MeSH)}

*Surgical Wound Dehiscence [epidemiology] [prevention \& control]; Digestive System Surgical Procedures [*adverse effects]; Elective Surgical Procedures [*adverse effects]; Enema [methods]; Fecal Incontinence [etiology] [prevention \& control]; Gastrointestinal Contents; Laxatives [administration \& dosage]; Preoperative Care [ ${ }^{*}$ methods]; Randomized Controlled Trials as Topic; Surgical Wound Infection [epidemiology] [prevention \& control]

\section{MeSH check words}

Humans 